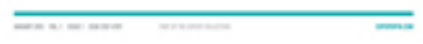

\title{
OPPEINION
}

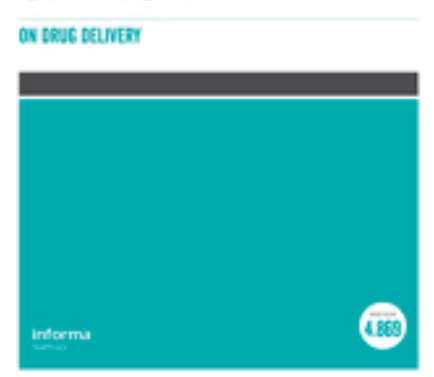

Please download and read the instructions before proceeding to the peer review

\section{Profiling of drug crystallization in the skin}

\begin{tabular}{|r|l|}
\hline Journal: & Expert Opinion on Drug Delivery \\
\hline Manuscript ID & EODD-2020-ST-0135.R1 \\
\hline Manuscript Type: & Original Research \\
\hline Keywords: & $\begin{array}{l}\text { Stratum corneum, drug crystallization, confocal Raman spectroscopy, } \\
\text { SAXS/WAXS, synchrotron }\end{array}$ \\
\hline \multicolumn{2}{|l}{} \\
\hline
\end{tabular}

\section{SCHOLARONE ${ }^{m}$ Manuscripts}




\begin{abstract}
Background: Drug crystallization following application of transdermal and topical formulations may potentially compromise the delivery of drugs to the skin. This phenomenon was found to be limited to the superficial layers of the stratum corneum $(\sim 7 \mu \mathrm{m})$ in our recent reports and tape stripping of the skin samples was necessary. It remains a significant challenge to profile drug crystallization in situ without damaging the skin samples.
\end{abstract}

Methods: This work reports the application of an X-ray microbeam via synchrotron SAXS/WAXS analysis to monitor drug crystallization in the skin, especially in the deeper skin layers. Confocal Raman spectroscopy (CRS) was employed to examine drug distribution in the skin to complement the detection of drug crystallization using SAXS/WAXS analysis.

Results: Following application of saturated drug solutions (ibuprofen, diclofenac acid and salts), CRS depth profiles confirmed that the drugs generally were delivered to a depth of $\sim 15-20 \mu \mathrm{m}$ in the skin. This was compared with the WAXS profiles that measured drug crystal diffraction at a depth of up to $\sim 25 \mu \mathrm{m}$ of the skin.

Conclusion: This study demonstrates the potential of synchrotron SAXS/WAXS analysis for profiling of drug crystallization in situ in the deeper skin layers without pretreatment for the skin samples.

\title{
Keywords:
}

Stratum corneum; drug crystallization; confocal Raman spectroscopy; SAXS/WAXS; synchrotron
Abbreviation
CRS: confocal Raman spectroscopy
DFA: Diclofenac acid
DF Na: Diclofenac sodium
DF DEA: Diclofenac diethylamine 
IBU: Ibuprofen

PG: propylene glycol

PSC: Porcine stratum corneum

SAXS: Small-angle X-ray scattering

SC: Stratum corneum

WAXS: Wide-angle X-ray scattering

$\mathrm{XRD}$ : X-ray diffraction 


\section{INTRODUCTION}

Drug delivery through the skin is challenging because of the barrier properties of the stratum corneum (SC). Multiple approaches to overcome this barrier have been extensively explored and yet the amounts of drugs that may be transported into the skin remain relatively low as compared to conventional drug delivery routes such as oral delivery. In the early 1950s and 1960s, several studies proposed that a drug "reservoir" may be formed in the skin following topical application of various formulations [1-3]. More recently the possibility of actives being "stranded" in the SC because of crystallization in the SC has also been confirmed [4-6].

In order to address this problem of poor skin delivery, several studies have focused on understanding drug crystallization in and on the skin. Using stimulated Raman scattering ibuprofen crystallization on the skin was reported following application of the drug in a propylene glycol (PG) solution $[7,8]$. We recently reported the application of ATR-FTIR spectroscopy and probe-based nano-characterization approaches to confirm the formation of drug crystals up to $\sim 7 \mu \mathrm{m}$ in the skin $[5,6]$. Hadgraft and Lane [4] first demonstrated the presence of drug crystals in the skin in vivo at a depth of 1.9 $\mu \mathrm{m}$ using confocal Raman spectroscopy (CRS) following application of hydrocortisone in dimethyl sulphoxide (DMSO). However, because of the sensitivity of the instruments used to date, there is little or no information on the formation of drug crystals and nuclei in the deeper layers of the skin. Importantly, our previous spectroscopic and probebased nano-characterizations are invasive approaches where the skin was tapestripped to allow the examination of drug crystallisation in the inner skin layers.

In the present work, we used X-ray scattering or diffraction (XRD) to investigate detection of drug crystals formed in situ in the deeper layers of the skin, after application of preparations with high drug thermodynamic activity. Both small-angle (SAXS) and wide-angle (WAXS) X-ray scattering were used because SAXS and WAXS can be measured at the same time but generate different $X$-ray scattering profiles depending on the diffraction angles. SAXS is also of particular benefit when examining large structural units (structural features with large repeat distances) in a sample. This is particularly useful when studying skin components such as lipid lamellar phases in the SC or collagen in the dermis. On the other hand, substances with smaller structural units such as drug crystals demonstrate diffraction at a larger 
angle in the WAXS profiles. This unique characteristic should enable detection and differentiation of the X-ray scattering by drug crystals from the skin components.

In this study, we examine drug crystallization in the skin in situ using synchrotron SAXS/WAXS as a function of depth. As drug in the solubilized form is not detected with XRD, CRS was used to monitor drug transport and crystallization as a function of depth. Solutions of ibuprofen (IBU), diclofenac acid (DFA) and two DFA salts diclofenac sodium (DF Na) and diethylamine (DF DEA) in two solvents - PG or dimethyl sulphoxide (DMSO) - were investigated in porcine skin. IBU and diclofenac are nonsteroidal anti-inflammatory drugs applied topically for management of pain and inflammation [9, 10]. PG and DMSO are known to have strong drug solubilizing capacities and allow manipulation of drug thermodynamic activity on and in the skin. These solvents were also previously investigated for their ability to trigger crystallization of the chosen drugs in the skin $[5,6]$.

\section{MATERIALS AND METHODS}

\subsection{Materials}

Ibuprofen (IBU) was a gift from Wyeth Pharmaceuticals (Havant, UK). Diclofenac acid (DFA), diclofenac sodium (DF Na) and DF DEA were purchased from AK Scientific Inc. (Union City, CA, US). Propylene glycol (PG) and dimethyl sulphoxide (DMSO) were obtained from Sigma-Aldrich (Gillingham, UK). Transcutol ${ }^{\circledR}$ was obtained from Gattefossé (Saint-Priest, France). Full-thickness porcine skin tissues were removed from porcine ear skin obtained from a local abattoir and stored at $-20{ }^{\circ} \mathrm{C}$ before use $[5,6]$. The skin tissues were thawed before preparation.

\subsection{Preparation of saturated solutions}

Saturated solutions were prepared by adding an excess amount of drug (IBU, DFA, DF $\mathrm{Na}$ and DF DEA) to PG and DMSO in an oven followed by agitation for $48 \mathrm{~h}$ at 32 $\pm 1^{\circ} \mathrm{C}$ as described previously [5]. The solutions were centrifuged to obtain supernatant for solubility determination using HPLC. 


\subsection{HPLC analysis}

Quantification of drug content was performed using an Agilent 1100 Series G1311A quaternary pump (Hewlett Packard, Santa Clara, CA, US) (flow rate $=1.2 \mathrm{~mL} / \mathrm{min}$ ) with a G1315B Diode Array Detector set at $220 \mathrm{~nm}$ for IBU and $277 \mathrm{~nm}$ for DFA and DFA salts. The stationary phase was a Shiseido Capcell Pak $\mathrm{C}_{18} 5 \mu \mathrm{m}$ column $(250 \mathrm{x}$ $4.6 \mathrm{~mm}$, Tokyo, Japan) attached to a SecurityGuard ${ }^{\mathrm{TM}}$ guard column with a $\mathrm{C}_{18}$ cartridge (Phenomenex, Macclesfield, UK). The mobile phase for IBU samples was $80 \%$ methanol, $20 \%$ water and $0.1 \%$ TFA. Samples containing IBU were injected via a 25 $\mu \mathrm{L}$ loop and the retention time was $5.8 \mathrm{~min}$. The mobile phase for DFA and DFA salts consisted of $70 \%$ acetonitrile, $30 \%$ water and $0.1 \%$ TFA. These samples were injected via a $20 \mu \mathrm{L}$ loop and the retention time was $4.8 \mathrm{~min}$. The concentration calculated from the AUC was used to develop calibration curves. This HPLC method was validated according to ICH guideline Q2(R1) [9].

\subsection{In vitro drug and solvent distribution study using confocal Raman spectroscopy (CRS)}

The in vitro drug distribution was measured using a confocal Raman spectrometer (Model 3510 Skin Composition Analyzer, River Diagnostics, Rotterdam, The Netherlands). A dose $\left(95 \mu \mathrm{L} / \mathrm{cm}^{2}\right)$ of a saturated solution of each drug in both $P G$ and DMSO was applied to a delineated area of porcine ear skin $\left(2 \times 2 \mathrm{~cm}^{2}\right)$ for $30 \mathrm{~min}$ at room temperature. The sites were gently wiped with dry tissues to remove excess solution before analysis. The CRS is equipped with two fiber-coupled diode-pumped lasers with two different wavelengths $(671 \mathrm{~nm}$ and $785 \mathrm{~nm})$. Spectral data collection in the high wavenumber region $\left(2500-4000 \mathrm{~cm}^{-1}\right)$ was conducted using a lowerwavelength laser $(671 \mathrm{~nm})$ while the spectral information in the fingerprint region (400 - $1800 \mathrm{~cm}^{-1}$ ) was recorded using a $785 \mathrm{~nm}$ laser with a spectral resolution of $4 \mathrm{~cm}^{-1}$. The laser light is focused on the skin through an oil-immersion microscope objective at a well-defined depth, adjusted by a high precision piezo-electric focusing drive. The tissue-scattered light, passing through the same objective, is focused onto an optical fiber acting as the confocal pinhole, rejecting signals from out-of-focus regions in the skin. The scattering Raman signal is detected with an air-cooled, high sensitivity backilluminated, deep depletion CCD camera (1024 × 128 pixels). An internal calibration for the instrument was conducted daily before any measurements and a signal-to- 
noise ratio of $30-38$ was considered acceptable for use. Measurements were taken in a temperature-controlled room $\left(23 \pm 1^{\circ} \mathrm{C}\right.$ and $30-40 \%$ relative humidity). The measurement acquisition time was $0.5 \mathrm{~s}$ per spectrum for water content profiles and $10 \mathrm{~s}$ per frame for fingerprint profiles. Scans of $4 \mu \mathrm{m}$ steps over a total depth of $40 \mu \mathrm{m}$ into the skin were collected for all control and treatment sites. The measurements were repeated by positioning the laser on another area until a total of eight scans was collected. Data were recorded using Riverlcon ${ }^{\circledR}$ software Version 3.0 and analyzed using Skin Tools ${ }^{\circledR}$ software Version 2.0 (River Diagnostics, Rotterdam, The Netherlands). Data were also plotted using Matlab (The Math-works, Natick, MA, US) for comparison with the SAXS/WAXS results.

The drug signal required for the fitting algorithm was obtained from a $200 \mathrm{mg} / \mathrm{mL}$ drug solution in either PG (for IBU, DF Na and DF DEA) or Transcutol ${ }^{\circledR}$ (for DFA). This signal was subtracted from the solvent signal (PG or Transcutol $^{\circledR}$ ). Transcutol ${ }^{\circledR}$ was used for DFA because the low solubility of DFA in PG generated a weak drug signal. The in vitro drug (and solvent) signal from the Raman skin spectrum was normalized to the keratin content because the absolute Raman signal intensity of in vitro skin spectra decreases in the deeper layers of the skin [10]. The skin water profile was determined by taking the ratio of the integrated signal of water (O-H stretching, 3350 $\left.-3550 \mathrm{~cm}^{-1}\right)$ to that of protein $\left(\mathrm{CH}_{3}\right.$ stretching, $\left.2910-2965 \mathrm{~cm}^{-1}\right)$. The SC thickness was determined by fitting this average water profile into a customized algorithm written in Matlab (The Math-works, Natick, MA, US). The boundary between the SC and stratum granulosum shows a large discontinuity in water content and allows estimation of the SC thickness [11,12]. The SC thickness was calculated before (control) each experiment.

\subsection{Synchrotron SAXS/WAXS experiments}

\subsubsection{Mounting of skin samples}

The SAXS/WAXS experiments were conducted with porcine ear skin (untreated/control and treated skin samples) at room temperature using a U-shaped sample holder, printed with a 3D printer (Makerbot ${ }^{\circledR}$ Replicator $^{\mathrm{TM}}$ 2; Makerbot $^{\circledR}$, Brooklyn, NY, USA) as shown in Figure 1. 
The skin was carefully placed on a glass slide with the dermis side facing up. A thin slice of the skin ( $\sim \mathrm{mm}$ thick) was cut using a scalpel from the dermis side to the surface of the skin on a glass slide. This skin sample was then sandwiched between two glass slides with vacuum grease. The sample and glass slides were fitted into the sample holder with the dermis side facing down (Figure 1). A donor compartment ( 2 $\times 0.1 \mathrm{~cm}^{2}$ ) was also created using vacuum grease. A cover glass slide was used to carefully flatten the surface edges.

The porcine ear skin was mounted in the path of the beam in a horizontal orientation with the cross-sectioned face of the skin perpendicular to the incident beam direction. The cross-sectioned face of the skin closest to the X-ray source is the anterior face while the opposite side is the posterior face (Figure 2A). Skin tissue has a soft structure that is difficult to handle when cut into small pieces. Owing to the undulated skin surface, the SAXS/WAXS scan was performed only when the anterior skin surface edge (adjacent to the microscope) was at a lower position than the posterior surface edge (Figure 2). In this work, the use of glass slides (thickness $=2 \mathrm{~mm}$ ) greatly reduced the transmitted intensity to approximately 0.1 times that of the incident X-ray. This resulted in weak diffraction in the scattering profiles.

The scan started from $30 \mu \mathrm{m}$ above the anterior skin surface edge before moving vertically towards the inner layer with a scanning step size of $5 \mu \mathrm{m}$. This was controlled using a stepping motor (Sigmakoki Ltd., Japan) coupled with a microscope which permitted sample positioning with a microscopic resolution of $\sim 2 \mu \mathrm{m}$. A total sequential series of $200 \mu \mathrm{m}$ was obtained for the skin layer but the first two scans (10 $\mu \mathrm{m})$ were not recorded by the system. These steps were carried out repetitively (at least 10 times) and horizontally across the skin sample.

To validate this experimental setup, the drug powder was placed in the donor compartment (IBU and DFA) before scanning using SAXS/WAXS. This step is important to ensure that diffraction of drug crystals detected in WAXS profiles scanning inside the skin was a result of drug recrystallization from the saturated solutions of drug. The experiment was repeated by filling the donor compartment with a dose of $20 \mu \mathrm{L}\left(>95 \mu \mathrm{L} / \mathrm{cm}^{2}\right)$ of a saturated drug solution. After 30 min permeation, any excess liquid on the skin was gently removed with dry cellulose filter papers. This sample was then scanned immediately using SAXS/WAXS. The total scan time for each sample was maintained at $30 \mathrm{~min}$ and the experiment was repeated from the permeation step 
where conducted. For the pure reference drug samples and their crystals recrystallized from the saturated solution, samples were sandwiched between Kapton ${ }^{\circledR}$ tape (DuPont ${ }^{\mathrm{TM}}$, Wilmington, DE, US).

\subsubsection{SAXS/WAXS configuration}

Both SAXS and WAXS were performed simultaneously at the BL40XU (High Flux Beamline) of the SPring-8 synchrotron station (Hyogo, Japan). A high-flux beam from a helical undulator $(\lambda=0.83 \AA$ ) was focused with two mirrors placed horizontally and vertically [13]. The X-ray energy was $15.0 \mathrm{keV}$ with an energy bandwidth of about $3 \%$. The X-ray microbeam was created by passing through a pinhole of $5 \mu \mathrm{m}$ in diameter. The sample-to-detector distance was adjusted to approximately $2 \mathrm{~m}$ and $0.1 \mathrm{~m}$ for SAXS and WAXS, respectively. SAXS and WAXS profiles were recorded on a cooled CCD camera (1344 × 1024 pixels, ORCAll-ER, Hamamatsu Photonics Ltd., Hamamatsu, Japan) coupled with an X-ray image intensifier (V5445P, Hamamatsu Photonics Ltd., Japan) and an X-ray flat-panel imager (1032 × 1032 pixels, C9728DK, Hamamatsu Photonics Ltd., Hamamatsu, Japan), respectively. The reciprocal spacing, $q$, was calibrated with silver behenate and cerium oxide at room temperature, where $q=2 \pi / d=4 \pi / \lambda \sin (\theta / 2), \theta$ is the scattering angle and $d$ is the repeat distance. This setup gave the $q$ range of $0.1<q<1.8 \mathrm{~nm}^{-1}$ for SAXS and $5<q<40 \mathrm{~nm}^{-1}\left(4^{\circ}<\theta<\right.$ $\left.30^{\circ}\right)$ for WAXS. The exposure time of the X-ray microbeam for both SAXS and WAXS was $1 \mathrm{~s}$. No radiation damage has been reported for both human [14] and porcine [15] skin samples for exposure times up to $15 \mathrm{~min}$ with a high-intensity $X$-ray $(\lambda=1.52 \AA)$. All the experiments were performed at room temperature $\left(25^{\circ} \mathrm{C}\right)$. The data analysis was performed using FIT2D software (ESRF, Grenoble, France). The SAXS diffraction pattern was circular averaged to obtain a radial intensity profile. The WAXS scattering profile is presented as the XRD images generated.

\section{RESULTS}

\subsection{Solubility study of saturated solutions}

The solubility data for the saturated solutions prepared using four different drugs at $32^{\circ} \mathrm{C}$ are shown in Table 1 . The saturated solubility of IBU in DMSO (777.9 \pm 48.0 
$\mathrm{mg} / \mathrm{mL}$ ) was almost three-times the saturated solubility in PG $(289.6 \pm 3.8 \mathrm{mg} / \mathrm{mL})$. The saturated solubility of DFA in DMSO $(677.9 \pm 19.5 \mathrm{mg} / \mathrm{mL})$ was more than 40 -fold that in $P G(16.7 \pm 0.2 \mathrm{mg} / \mathrm{mL})$. On the other hand, the saturated solubility of DF $\mathrm{Na}$ in DMSO $(148.7 \pm 9.3 \mathrm{mg} / \mathrm{mL})$ was only one-third of the value for PG $(385.5 \pm 18.4$ $\mathrm{mg} / \mathrm{mL}$ ). The values for saturated solubility of DF DEA in PG and DMSO were 236.5 $\pm 8.8 \mathrm{mg} / \mathrm{mL}$ and $175.8 \pm 18.5 \mathrm{mg} / \mathrm{mL}$. Most of the drug solutions in this study were also observed to be very viscous. All of the saturated solutions crystallized within 30 min when examined under a polarized light microscope except for the DFA-PG saturated solution (data not shown).

\subsection{In vitro drug and solvent distribution study using CRS}

The CRS depth profiles of model drugs across porcine ear skin following the application of saturated solutions are displayed in Figure 3. The integrated in vitro drug intensity was expressed in arbitrary units (a.u.) because this analytical method has not been calibrated for quantitative analysis to date. In general, these profiles showed that the drugs penetrated the skin up to $15-20 \mu \mathrm{m}$. The thickness of porcine stratum corneum (PSC) was estimated using CRS as $11.3 \pm 3.3 \mu \mathrm{m}$. This result is in line with the value for PSC $(11.15 \pm 1.52 \mu \mathrm{m})$ reported by Mahrhauser, et al. [21] using Raman spectroscopy.

For IBU, both the IBU-PG and IBU-DMSO saturated solutions showed a similar drug distribution profile but a very strong drug signal was found close to the skin surface (depth zero) for the DMSO solution, reflecting the higher solubility of IBU in DMSO.

A similar observation was noted after application of a saturated solution of DFA in DMSO where a very high drug signal intensity was detected up to $8 \mu \mathrm{m}$ in the skin. $A$ low signal of DFA was detected in the skin following application of the DFA-PG saturated solution. Permeation of DF $\mathrm{Na}$ and DF DEA into the skin using PG resulted in a higher drug signal at the skin surface than DMSO, again reflecting high drug solubility of DF Na and DF DEA in PG.

The CRS depth profiles of the solvents used were also evaluated (Figure 4). PG showed a higher intensity below the skin following the application of saturated solutions of DF $\mathrm{Na}$ and DF DEA as compared with DFA (Figure 4A). A lower intensity was observed for PG for the IBU solution. A similar pattern was also observed for the 
depth profiles of DMSO (Figure 4B) but a relatively high intensity of DMSO was detected in the deeper layers of the skin as compared with PG. A large difference in the intensity of DMSO below the skin was reported following the application of saturated solutions of DF $\mathrm{Na}$ in comparison with the other model drugs.

\subsection{Synchrotron SAXS/WAXS}

\subsubsection{Pure drugs and crystals}

The SAXS scattering profiles of pure drugs and their crystals (not shown) showed the absence of diffraction within the $q$ range of $0.1-1.8 \mathrm{~nm}^{-1}$. In fact, the general absence of peaks at $\mathrm{q}<5 \mathrm{~nm}^{-1}\left(\sim 4^{\circ}\right)$ indicates that it is likely that there are no peaks at even lower angles for these drug samples.

The WAXS scattering profiles of pure drug powder and crystals are shown as spot patterns in Supplemental Files (Figure S1). A random oriented (isotropic) sample such as a crystalline powder results in a scattering pattern with equal intensities along concentric circles/semicircles [22]. This is similar to the X-ray powder diffraction (XRPD) analysis where all orientations are present in a powder sample. The creation of intensive spots (reflections) instead of equal intensities along concentric circles/semicircles indicates that the sample is a single crystal in a specific orientation with respect to the incident X-ray beam. A difference in this pattern relies on the spacing ( $d$ spacing) between a unit cell and its atomic planes in the lattice. In addition, the size of the X-ray microbeam $(5 \mu \mathrm{m})$ is sufficiently small to detect single-crystal diffraction in this study. A large beam size such as the SAXS/WAXS beamline in the Australian Synchrotron (beam size $=200 \times 100 \mu \mathrm{m}$ ), however, gives powder diffraction concentric patterns [23].

\subsubsection{Skin samples}

\subsubsection{Untreated skin (control)}

The SAXS scattering profile of porcine ear skin without any treatment is shown in Figure 5. The SAXS scattering profiles exclude the data with $q>1 \mathrm{~nm}^{-1}$ because no reflection was detected beyond this value. Two significant peaks were highlighted at $q=0.29 \mathrm{~nm}^{-1}$ and $0.48 \mathrm{~nm}^{-1}$ corresponding to the $d$ spacings of $21.57 \mathrm{~nm}$ and 13.06 
$\mathrm{nm}$ respectively. This observation is consistent for all the scans as a function of depth. The scans below the anterior skin surface edge are denoted with a negative (-) sign. At a larger intensity scale, a third sharp peak can be clearly detected at $q=0.87 \mathrm{~nm}^{-1}$ ( $d$ spacing $=7.25 \mathrm{~nm}$ ). Between the two sharp peaks at $q=0.48 \mathrm{~nm}^{-1}$ and $0.87 \mathrm{~nm}^{-1}$, several weak reflections were also observed at $q=0.57 \mathrm{~nm}^{-1}(d$ spacing $=10.95 \mathrm{~nm})$, $0.68 \mathrm{~nm}^{-1}(d$ spacing $=9.27 \mathrm{~nm})$ and $0.77 \mathrm{~nm}^{-1}(d$ spacing $=8.15 \mathrm{~nm})$.

The spacing observed was very similar to that of the axial periodicity of collagen in the human dermis as described by Mérigoux, et al. [24] and Cocera, et al. [25]. This axial molecular packing in the fibrils is formed by regular staggering of adjacent molecules, resulting in repetitive intervals of $65.2 \mathrm{~nm}$ consisting of gaps and overlapped regions $[26,27]$. This was also reported in porcine skin (dorsal region) by Rubio, et al. [28]. The regular appearance of collagen scattering in this profile is from the dermis.

The diffraction of collagen fibers from the $3^{\text {rd }}$ to the $9^{\text {th }}$ order reflections are similar to those observed by Cocera, et al. [25] and Rubio, et al. [28]. The absence of the firstorder reflection in this study is because of a shorter sample-to-detector distance of 2 $\mathrm{m}$. Also, the detection of odd diffraction orders $\left(3^{\text {rd }}, 5^{\text {th }}\right.$ and $\left.9^{\text {th }}\right)$ is far more obvious than the even orders. This has been reported by Fratzl, et al. [29] for studies on the rat tail tendon where the different behavior of odd and even orders was observed during stretching. Cocera, et al. [25] also described this phenomenon in the skin.

Apart from the limitation of the sample-to-detector distance, the mounting of the skin perpendicular to the beam path may restrict the detection of the scattering features of collagen in the lateral arrangement. This includes the diameter of the fibrils (the cylindrical shapes of collagen) with spacing of $\sim 85-110 \mathrm{~nm}$.

In this work, the scattering patterns from the components in the SC were not detected. Previously, Bouwstra, et al. [15] classified the major periodicities of PSC intercellular lipids present in SAXS scattering patterns into two lamellar phases: a short periodicity phase (SPP, $6 \mathrm{~nm}$ ) and a long periodicity phase (LPP, $13.2 \mathrm{~nm}$ ). This is similar to the SAXS profiles of human stratum corneum reported by the same group of researchers [14]. Cocera, et al. [25] reported the reflections derived from the SC lipid in the human epidermis sample containing SC while the skin samples of both epidermis and dermis showed only the reflections of collagen fibers. Likewise, a similar experimental setup 
with an overlapping of the dermis of porcine skin used in this study detected the same results reported by Cocera, et al. [25].

The undetectable scattering reflections from the SC lipids, in fact, were not a result of the disturbance of the SC lipid pattern by the collagen pattern in dermis. Considering the inclusion of SC in the epidermis as an intact structure in the skin sample, these epidermal components, especially highly ordered lipids are surrounded by nonordered materials. In addition, the amount of SC lipid is relatively low as compared with that of the collagen content, the latter constituting $75 \%$ of the dermis. Therefore, the undetectable scattering pattern of the components in the epidermis (mostly SC lipids) could result from a low proportion of these components in the porcine skin sample.

On the other hand, the WAXS diffraction profiles of porcine ear skin (control sample) showed no diffraction (not shown). This indicates the absence of elements with small structural units which diffract at a larger angle such as drug crystals.

\subsubsection{Validation of experimental setup}

To validate detection of crystalline drug, if present, pure drug powder was applied onto mounted skin samples. In this case, drug crystal diffraction recorded in WAXS profiles should only present at and/or above the anterior skin surface edge. These data confirm that the detection of drug crystal diffraction at and/or below this surface edge after application of saturated drug solutions is likely due to drug re-crystallization from these solutions. Also, it is important to confirm that there was no contamination of the skin sample. For the validation process, two pure drug powder samples used in the preparation of saturated solutions (IBU and DFA) were selected.

The SAXS scattering profiles of porcine skin prepared for validation showed a similar pattern as demonstrated in the untreated skin samples (Figure S2). The scattering indicated the presence of dermal collagen in the depth scan of the cross-sectioned skin with significant reflections of the $3^{\text {rd }}$ and $5^{\text {th }}$ orders.

The diffraction of drug crystals against the background observed in the WAXS diffraction patterns indicated the detection of IBU and DFA pure drug powder (Figure S3). The presence of IBU pure drug powder showed diffraction at/above the anterior 
skin surface edge. Detection of diffraction from drug crystals for DFA was only evident in one of the samples, $20 \mu \mathrm{m}$ to $10 \mu \mathrm{m}$ above this surface edge. There were no crystals detected in another run probably due to the random application of drug powders of different particle sizes. From these observations, no crystals were identified below the anterior surface edge. In this validation step, the absence of drug crystals below the anterior skin surface edge was anticipated as pure drug powder was spread on the skin.

\subsubsection{Application of saturated drug solutions}

The SAXS/WAXS experiments were repeated by applying saturated drug solutions over $30 \mathrm{~min}$. Identical observations as reported for control skin samples were observed for all SAXS scattering profiles (Figure S4) apart from the differences in the intensities of the reflections. Two reflections reported at $q=0.29 \mathrm{~nm}^{-1}$ and $0.48 \mathrm{~nm}^{-1}$ were assigned to the $3^{\text {rd }}$ and $5^{\text {th }}$ orders of the axial periodicity of dermal collagen.

However, in most of the SAXS scattering profiles as a function of depth, the initial reflections (some up to $50-60 \mu \mathrm{m}$ into the skin) were greatly attenuated or lost. This suggests an impact of the solvents on the structural conformation of collagen. PG has previously been shown to have a destabilizing effect on the collagen macromolecule of calf skin by decreasing the denaturation temperature of the protein [30]. The presence of an exposed methyl group in PG allows its interaction with non-polar regions of the collagen molecule, causing a destabilization in the collagen molecule [31]. Later, Kuznetsova, et al. [32] and Yeh and Hirshburg [33] noted that the major effect of $P G$ on promoting denaturation of collagen and other proteins originated from the ability of $P G$ to enhance collagen solubility and disrupt the hydrogen-bondfacilitated-water bridges between the collagen triple helices.

On the other hand, DMSO showed powerful effects on disruption of the intra- and intermolecular cross-links of collagen fibers [34]. This was also supported by Zimmerley, et al. [35] who observed changes in the intrinsic structure of skin collagen by DMSO at the sub-micron level. DMSO interferes with the highly ordered collagen I fibers by increasing the spacing between microfibrils. The decomposition of collagen fibers in the presence of DMSO may also contribute to a diminished degree of organizational symmetry of microfibrils. 
In this work, it is believed that permeation of these solvents into the skin disrupted the structure of dermal collagen in a similar way. This resulted in a reduced intensity of the reflections from diffraction from collagen in the dermis in the experiment conducted. Considering drug crystallization as a heterogeneous process, the probability of drug crystal detection is very low. To attempt to detect crystals, should they be present, each sample was measured at least 10 times. The results shown in this study represent the prominent WAXS profiles showing the diffraction of drug crystals only.

The corresponding WAXS diffraction patterns of drug crystals after a 30-min application of the IBU saturated solution on porcine skin are depicted in Figure 6. WAXS profiles without drug crystal diffraction were not included in this figure. Thus, the number of WAXS profiles shown depends on the depth of drug crystal diffraction detected (a maximum of $25 \mu \mathrm{m}$ into the skin, although scans were performed up to $165 \mu \mathrm{m}$ into the skin). When applied as a saturated solution in PG, drug crystallization was detected up to $10 \mu \mathrm{m}$ into the skin (Figure 6A). However, the diffraction of IBU crystals was detected at depths of $20 \mu \mathrm{m}$ after application of a saturated solution in DMSO. For both IBU saturated solutions, only one of the two replicates showed the diffraction of crystals in the skin.

In the case of DFA, drug crystals were found up to $5 \mu \mathrm{m}$ in the skin when applied in DMSO (Figure 7). When applied in PG, no drug crystals were detected.

Application of the DF Na-DMSO solution resulted in the presence of crystals at a greater depth in the skin $(25 \mu \mathrm{m})$ as compared with the DF Na-PG combination (10 $\mu \mathrm{m})$ (Figure 8).

For solutions of the diethylamine salts, diffraction from drug crystals was observed up to $15 \mu \mathrm{m}$ and $20 \mu \mathrm{m}$ in the skin (

Figure 9).

Overall, it is difficult to detect drug crystallization in the deeper layers of the skin. This suggests a low probability of drug crystallization. The weak diffraction pattern in the deeper layers of the skin may also be a result of the random position of these newly formed drug crystals in the skin because $d$ spacing and atomic planes of the crystals determine the diffraction pattern. 


\section{DISCUSSION}

Drug crystallization is commonly initiated by nucleation processes, converting a thermodynamically unstable system into a stable state. The same process may occur when a topical formulation with high drug thermodynamic activity is applied on the skin. While the CRS depth profiles (Figure 3) showed that drug permeated up to $15-$ $20 \mu \mathrm{m}$ into the skin, the differentiation of solid crystals from saturated drug solutions is difficult to achieve as a function of skin depth because of the unknown location of drug crystals in the skin and the limited resolution of CRS for differentiating drug crystals from the solubilized form of the drug. A complementary technique using SAXS/WAXS analysis was employed here to compare the detection of drug crystal diffraction in the WAXS profiles with the CRS depth profiles as shown in Figure 10. Overall, WAXS profiles confirmed the presence of drug crystals up to a depth of $20-$ $25 \mu \mathrm{m}$ in the skin.

Even though a concentrated drug solution should have a higher probability of drug crystallization, this does not correlate well with the detection of drug crystal diffraction in the WAXS diffraction profiles as a function of skin depth. Among all the combinations of drugs and solvents, the saturated solution of DFA in PG was the only system which showed no drug crystal diffraction in WAXS profiles. This may reflect a lower drug solubility in PG. DFA was also found to have a very low signal intensity in the skin when applied in PG as shown in the CRS profiles.

In this work, diffraction from drug crystals was detected deeper than the SC thickness estimated using CRS $(\sim 11 \mu \mathrm{m})$. The data indicates that drug crystallization may occur beyond the $\mathrm{SC}$, including in the viable epidermis and dermis. It should be borne in mind that there is an absence of sink conditions with the in vitro setup in this study. Drug that has permeated through the SC may accumulate and slowly crystallize in the deeper layers of the skin over time. Consequently, this may result in the detection of drug crystal diffraction in the WAXS diffraction profiles, up to $20-25 \mu \mathrm{m}$ into the skin. The lack of sink conditions may also result in the accumulation of solvent but this does not prevent drug from recrystallization in the deeper layers of the skin. This is because the formulation is in a high thermodynamic state and nucleation can happen spontaneously. The accumulation of solvent in the skin, however, may explain the weak reflections recorded in some WAXS profiles because of limited nucleation in the deeper layers of the skin. 
Given that X-ray analysis is not suitable for in vivo studies in human subjects, an in vivo study could not be carried out using the same experimental design. Although this study was carried out using an in vitro setup, this work offers advantages over other techniques previously reported by our group including ATR-FTIR spectroscopic analysis and localized nano-thermal analysis [5,6]. These include the ability of synchrotron SAXS/WAXS analysis to detect and locate accurately drug crystallization in the skin in situ without any pretreatment. Moreover, the X-ray microbeam is sensitive to the crystals formed in the deeper layers of the skin, albeit the drug crystal diffractions are weak.

Previously the exploration of drug crystallization in the skin via different characterisation methods was achieved primarily by creating an extremely unstable drug system with a high drug thermodynamic activity. This is also a pre-requisite to allow examination of drug crystallization in the skin. Even though drugs are not present in an unstable state in commercialized products, there are formulation designs that employ the concept of saturated or supersaturated systems to enhance drug permeation through the skin [36]. These formulations usually contain a high amount of highly volatile solvents such as alcohols that promote a high drug thermodynamic activity following application. The approach has also been investigated for ibuprofen [37], fentanyl [38], oxybutynin [39] and piroxicam [40]. Enhancing drug permeation using supersaturated systems has benefits in avoiding disturbance to the structure of the SC and reducing the cost of formulations [41]. Although the use of saturated systems of drugs may not be practical when formulating topical products, depletion of solvents from a typical formulation is likely to initiate drug crystallisation, resulting in a transient thermodynamic instability of the formulation. This was previously observed to affect the permeation of IBU across porcine skin under the influence of PG $[42,43]$. PG crosses the skin barrier more quickly than the drug as observed by Trottet, et al. [42] and this results in solvent loss from the formulation applied. Also, solvent evaporation, mainly PG, limits the role of PG in enhancing permeation of IBU $[43,44]$. Therefore, the consideration of drug crystallisation, be it in the skin or in the formulations, is highly important and this phenomenon can be minimised by using anti-nucleant agents, suppressing nucleation and crystal growth. The anti-nucleant agents used are mostly polymers, such as hydroxypropyl methylcellulose, methylcellulose, polyvinyl pyrrolidine, and polyethylene glycol $400[16,38,40,45]$. The 
addition of polymers to stabilise an unstable thermodynamic system is usually achieved by establishing polymer-drug interactions and forming a barrier to prevent the incoming drug molecules adhering to the drug crystal faces.

\section{CONCLUSIONS}

While drug crystallization in the skin was reported in previous studies, most of the experiments required procedures to remove the skin layers, namely tape stripping, to confirm the presence of drug crystals formed in the skin layers. The current work demonstrates a non-invasive approach that overcome the problems of skin disruption during pre-treatment of samples and the sensitivity limit of the instruments used previously. Synchrotron SAXS/WAXS analysis with an X-ray microbeam (5 $\mu \mathrm{m}$ beam size) allowed us to examine drug crystals in the deeper skin layers in situ that cannot be achieved using the previous characterization methods. Even though CRS generally showed drug penetration to a depth of up to $15-20 \mu \mathrm{m}$, the diffraction studies detected drug crystals present at a deeper skin layers $(20-25 \mu \mathrm{m})$. This indicates that drug crystallisation may happen in the viable epidermis and probably the dermis, a finding that has not been reported to date. The observation may also reflect the lack of sink conditions in the in vitro setup, followed by the accumulation of drugs in the deeper skin layers. Drug crystallisation in the skin may not be perceived as a common issue with currently marketed transdermal and topical products. However, we strongly believe that this event can be presented as a transient phenomenon because of the formulation design (saturated/supersaturated system) or the depletion of excipients, namely the solvents. Hence, an improved understanding of the phenomenon through this proof of concept study should allow the prediction of drug crystallization in the skin. Ultimately, this should inform better formulation of products with cost-savings and associated patient benefits.

\section{Funding:}

This work was supported by Ministry of Education Malaysia for PhD funding of Choon $\mathrm{Fu}$ Goh. We also acknowledge travel funding provided by the International Synchrotron Access Program (ISAP) managed by the Australian Synchrotron, part of 


\begin{abstract}
ANSTO, and funded by the Australian Government" and the grant number for the synchrotron travel was ISP8044.
\end{abstract}

\title{
Declaration of interest:
}

The authors have no relevant affiliations or financial involvement with any organization or entity with a financial interest in or financial conflict with the subject matter or materials discussed in the manuscript. This includes employment, consultancies, honoraria, stock ownership or options, expert testimony, grants or patents received or pending, or royalties.

\section{Acknowledgments:}

The synchrotron radiation experiments were performed at the BL40XU of SPring-8 with the approval of the Japan Synchrotron Radiation Research Institute (JASRI) (Proposal No. 2014A1173). We would like to express our appreciation to Dr Noboru Ohta for his advice on experimental setup at Spring-8 and on data analysis as well as to Emeritus Professor Jonathan Hadgraft for his advice and supervision.

\section{REFERENCES}

\section{Papers of special note have been highlighted as: \\ * of interest \\ ** of considerable interest}

1. Malkinson FD, Ferguson EH. Percutaneous absorption of hydrocortisone-4$\mathrm{C}^{14}$ in two human subjects. Journal of Investigative Dermatology. 1955;25(5):281283.

2. Vickers $\mathrm{CH}$. Existence of reservoir in the stratum corneum: Experimental proof. Archives of Dermatology. 1963;88(1):20-23.

3. Stoughton RB. Dimethylsulfoxide (DMSO) induction of a steroid reservoir in human skin. Archives of Dermatology. 1965;91(6):657-660.

4. Hadgraft J, Lane ME. Drug crystallization - implications for topical and transdermal delivery. Expert Opinion on Drug Delivery. 2016;13(6):817-830. 


\section{** First demonstration in man of drug crystallization using confocal Raman spectroscopy}

5. Goh CF, Craig DQM, Hadgraft J, et al. The application of ATR-FTIR spectroscopy and multivariate data analysis to study drug crystallisation in the stratum corneum. European Journal of Pharmaceutics and Biopharmaceutics. 2017; 111:16-25.

\section{** In vitro work demonstrating drug crystallization in the skin}

6. Goh CF, Moffat JG, Craig DQM, et al. Monitoring Drug Crystallization in Percutaneous Penetration Using Localized Nanothermal Analysis and Photothermal Microspectroscopy. Molecular Pharmaceutics. 2019;16(1):359-370.

\section{** Detection drug crystals up to $\sim 7 \mu \mathrm{m}$ in the skin}

7. Belsey NA, Garrett NL, Contreras-Rojas LR, et al. Evaluation of drug delivery to intact and porated skin by coherent Raman scattering and fluorescence microscopies. Journal of Controlled Release. 2014;174:37-42.

8. Saar BG, Contreras-Rojas LR, Xie XS, et al. Imaging drug delivery to skin with stimulated Raman scattering microscopy. Molecular Pharmaceutics. 2011;8(3):969-975.

9. $\mathrm{ICH}$. Validation of Analytical Procedures: Text and Methodology Q2(R1) FDA; 2005.

10. Caspers PJ, Lucassen GW, Carter EA, et al. In vivo confocal Raman microspectroscopy of the skin: Noninvasive determination of molecular concentration profiles. Journal of Investigative Dermatology. 2001;116(3):434-442.

\section{** Demonstrates non-invasive method to evaluate drug distribution in the skin with depth profile}

11. Crowther JM, Sieg A, Blenkiron P, et al. Measuring the effects of topical moisturizers on changes in stratum corneum thickness, water gradients and hydration in vivo. British Journal of Dermatology. 2008;159(3):567-577.

12. Egawa M, Hirao T, Takahashi M. In vivo estimation of stratum corneum thickness from water concentration profiles obtained with Raman spectroscopy. Acta Dermato-Venereologica. 2007;87(1):4-8.

13. Inoue K, Oka T, Suzuki T, et al. Present status of high flux beamline (BL40XU) at SPring-8. Nuclear Instruments and Methods in Physics Research Section A: Accelerators, Spectrometers, Detectors and Associated Equipment. 2001;467-468, Part 1(0):674-677.

14. Bouwstra JA, Gooris GS, van der Spek JA, et al. Structural investigations of human stratum corneum by small-angle X-ray scattering. Journal of Investigative Dermatology. 1991;97(6):1005-1012. 
15. Bouwstra JA, Gooris GS, Bras W, et al. Lipid organisation in pig stratum corneum. Journal of Lipid Research. 1995;36(4):685-95.

16. lervolino M, Raghavan SL, Hadgraft J. Membrane penetration enhancement of ibuprofen using supersaturation. International Journal of Pharmaceutics. 2000;198(2):229-238.

17. Watkinson RM, Herkenne C, Guy RH, et al. Influence of ethanol on the solubility, ionization and permeation characteristics of ibuprofen in silicone and human skin. Skin Pharmacology and Physiology. 2009;22(1):15-21.

18. Mateus R. Spectroscopic and membrane transport evaluation of model topical formulations [Thesis]. London: University College London; 2013.

19. Minghetti $P$, Cilurzo $F$, Casiraghi $A$, et al. Ex vivo study of transdermal permeation of four diclofenac salts from different vehicles. Journal of Pharmaceutical Sciences. 2007;96(4):814-823.

20. Žilnik LF, Jazbinšek A, Hvala $A$, et al. Solubility of sodium diclofenac in different solvents. Fluid Phase Equilibria. 2007;261(1-2):140-145.

21. Mahrhauser D-S, Nagelreiter C, Gehrig S, et al. Assessment of Raman spectroscopy as a fast and non-invasive method for total stratum corneum thickness determination of pig skin. International Journal of Pharmaceutics. 2015;495(1):482484.

22. Schnablegger H, Singh $\mathrm{Y}$. The SAXS Guide. $2^{\text {nd }}$ ed. Austria: Anton Paar $\mathrm{GmbH} ; 2011$.

23. Boetker J, Rades T, Rantanen J, et al. Structural elucidation of rapid solutionmediated phase transitions in pharmaceutical solids using in situ synchrotron SAXS/WAXS. Molecular Pharmaceutics. 2012;9(9):2787-2791.

24. Mérigoux c, durand d, doucet j, et al. Supramolecular organisation of collagen fibrils in human tissues. ESRF Newsletter. Vol. 29. France: ESRF; 1997. p. 18-19.

25. Cocera M, Rodriguez G, Rubio L, et al. Characterisation of skin states by noncrystalline diffraction [10.1039/C1SM05716B]. Soft Matter. 2011;7(18):8605-8611.

26. Wess TJ, Orgel JP. Changes in collagen structure: Drying, dehydrothermal treatment and relation to long term deterioration. Thermochimica Acta. 2000;365(12):119-128.

27. Gobeaux F, Belamie E, Mosser G, et al. Cooperative ordering of collagen triple helices in the dense state. Langmuir. 2007;23(11):6411-6417.

28. Rubio L, Alonso C, Rodríguez G, et al. Bicellar systems as new delivery strategy for topical application of flufenamic acid. International Journal of Pharmaceutics. 2013;444(1-2):60-69.

29. Fratzl P, Misof K, Zizak I, et al. Fibrillar structure and mechanical properties of collagen. Journal of Structural Biology. 1998;122(1-2):119-122. 
30. Hart GJ, Russell AE, Cooper DR. The effects of certain glycols, substituted glycols and related organic solvents on the thermal stability of soluble collagen. Biochemical Journal. 1971;125(2):599-604.

31. Harrap BS. The effect of aliphatic alcohols on the thermal stability of tropocollagen under acidic conditions. International Journal of Protein Research. 1969;1(1-4):245-252.

32. Kuznetsova N, Chi SL, Leikin S. Sugars and polyols inhibit fibrillogenesis of type I collagen by disrupting hydrogen-bonded water bridges between the helices. Biochemistry. 1998;37(34):11888-11895.

33. Yeh AT, Hirshburg J. Molecular interactions of exogenous chemical agents with collagen - implications for tissue optical clearing. Journal of Biomedical Optics. 2006;11(1):014003-014003-6.

34. Erk Y, Raskin DJ, Mace M, et al. Dimethyl sulfoxide alteration of collagen. Annals of the New York Academy of Sciences. 1983;411(1):364-368.

35. Zimmerley M, McClure RA, Choi B, et al. Following dimethyl sulfoxide skin optical clearing dynamics with quantitative nonlinear multimodal microscopy. Applied Optics. 2009;48(10):D79-D87.

36. Davis AF, Hadgraft J. Effect of supersaturation on membrane-transport .1. Hydrocortisone acetate. International Journal of Pharmaceutics. 1991;76(1-2):1-8.

\section{* Supersaturation as a strategy to enhance drug permeation in the skin}

37. Iervolino M, Cappello B, Raghavan SL, et al. Penetration enhancement of ibuprofen from supersaturated solutions through human skin. International Journal of Pharmaceutics. 2001;212(1):131-141.

38. Santos $\mathrm{P}$, Watkinson $\mathrm{AC}$, Hadgraft $\mathrm{J}$, et al. Formulation issues associated with transdermal fentanyl delivery. International Journal of Pharmaceutics. 2011;416(1):155-159.

39. Santos $\mathrm{P}$, Watkinson AC, Hadgraft J, et al. Oxybutynin permeation in skin: The influence of drug and solvent activity. International Journal of Pharmaceutics. 2010;384(1-2):67-72.

40. Pellett MA, Castellano S, Hadgraft J, et al. The penetration of supersaturated solutions of piroxicam across silicone membranes and human skin in vitro. Journal of Controlled Release. 1997;46(3):205-214.

41. Pellett MA, Davis AF, Hadgraft J. Effect of supersaturation on membranetransport .2. Piroxicam. International Journal of Pharmaceutics. 1994;111(1):1-6.

42. Trottet L, Merly C, Mirza M, et al. Effect of finite doses of propylene glycol on enhancement of in vitro percutaneous permeation of loperamide hydrochloride. International Journal of Pharmaceutics. 2004;274(1-2):213-219. 
43. Tsai J-C, Cappel MJ, Flynn GL, et al. Drug and vehicle deposition from topical applications: Use of in vitro mass balance technique with minoxidil solutions. Journal of Pharmaceutical Sciences. 1992;81(8):736-743.

44. Intarakumhaeng R, Li SK. Effects of solvent on percutaneous absorption of nonvolatile lipophilic solute. International Journal of Pharmaceutics. 2014;476(12):266-276.

45. Raghavan SL, Trividic A, Davis AF, et al. Crystallization of hydrocortisone acetate: Influence of polymers. International Journal of Pharmaceutics. 2001;212(2):213-221.

** Demonstrates the use of polymers to inhibit drug crystallization 


\section{Legends:}

Figures:

Figure 1 (A) A U-shaped sample holder for mounting skin sample in SAXS/WAXS experiment and $(B)$ a three-dimensional view before and after assembling glass slides and porcine ear skin

Figure 2 Schematic of the sample holder mounted with porcine ear skin. The circle on the right shows the view from the anterior cross-sectioned face of skin perpendicular to the microscope as well as the X-ray microbeam.

Figure 3 CRS depth profiles of (A) IBU, (B) DFA, (C) DF Na and (D) DF DEA after 30min application of respective saturated solutions in PG (O) and DMSO (•) to porcine ear skin $(n=8$, mean $+S D)$

Figure 4 CRS depth profiles of (A) PG and (B) DMSO after 30-min application of various saturated drug solutions $(n=8$, mean $+S D)$

Figure 5 SAXS scattering profiles of cross-sectioned porcine ear skin as a function of depth (step size $=5 \mu \mathrm{m}$ ). The red and black curves indicate the scans at/above (20 to $0 \mu \mathrm{m})$ and below ( -5 to $-165 \mu \mathrm{m})$ the anterior skin surface edge, respectively. The intensities are in arbitrary units.

Figure 6 WAXS diffraction patterns of drug crystals after application of saturated solutions of IBU in (A) PG and (B) DMSO $(n=2)$. Weak reflections are enlarged in the same figure or highlighted in the red circle.

Figure 7 WAXS diffraction patterns of drug crystals after application of a saturated solution of DFA in DMSO $(n=2)$. Weak reflections are highlighted in the red circle.

Figure 8 WAXS diffraction patterns of drug crystals after application of saturated solutions of DF Na in (A) PG and (B) DMSO $(n=2)$. Weak reflections are highlighted in the red circle.

Figure 9 WAXS diffraction patterns of drug crystals after application of a saturated solution of DF DEA in (A) PG and (B) DMSO $(n=2)$. Weak reflections are enlarged in the same figure or highlighted in the red circle. 
Figure 10 CRS depth profiles following the application of various saturated solutions in PG and DMSO to porcine ear skin and depth profiles for drug crystal diffraction (*) in the WAXS diffraction profiles

Table:

Table 1 Saturated solubility of IBU, DFA, DF Na and DF DEA in PG and DMSO at $32^{\circ} \mathrm{C}(\mathrm{n}=3$, mean $\pm \mathrm{SD})$ 
Table:

Table 1 Saturated solubility of IBU, DFA, DF Na and DF DEA in PG and DMSO at $32^{\circ} \mathrm{C}(\mathrm{n}=3$, mean $\pm \mathrm{SD})$

\begin{tabular}{|c|c|c|c|}
\hline Drug & Solvent & Solubilit & (mg/mL unless otherwise specified) \\
\hline \multirow{3}{*}{ IBU } & PG & $289.6 \pm 3.8$ & $\begin{array}{c}160 \text { (lervolino, et al. [16] ), } 301.3 \\
\text { (Watkinson, et al. [17]), } 254 \text { (Mateus [18]) }\end{array}$ \\
\hline & & & \\
\hline & DMSO & $\begin{array}{l}777.9 \pm \\
48.0\end{array}$ & n.a. \\
\hline \multirow[b]{2}{*}{ DFA } & PG & $16.7 \pm 0.2$ & n.a. \\
\hline & DMSO & $\begin{array}{l}677.9 \pm \\
19.5\end{array}$ & n.a. \\
\hline \multirow{2}{*}{ DF Na } & PG & $\begin{array}{c}385.5 \pm \\
18.4\end{array}$ & $567 \pm 31$ (Minghetti, et al. [19]) \\
\hline & DMSO & $148.7 \pm 9.3$ & 165 mg/g* (Žilnik, et al. [20]) \\
\hline \multirow[b]{2}{*}{ DF DEA } & PG & $236.5 \pm 8.8$ & $384 \pm 14$ (Minghetti, et al. [19]) \\
\hline & DMSO & $\begin{array}{l}175.8 \pm \\
18.5\end{array}$ & n.a. \\
\hline
\end{tabular}

* Estimated from the drug solubility data plot from literature 
A

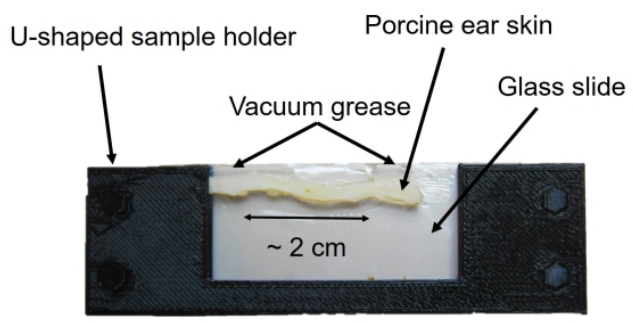

B

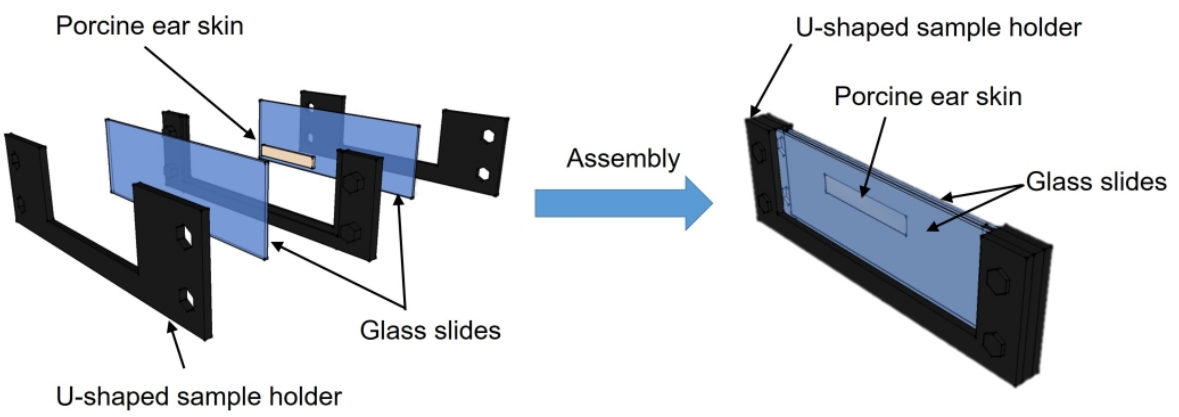

Figure 1 (A) A U-shaped sample holder for mounting skin sample in SAXS/WAXS experiment and (B) a three-dimensional view before and after assembling glass slides and porcine ear skin $558 \times 393 \mathrm{~mm}(150 \times 150 \mathrm{DPI})$ 
A

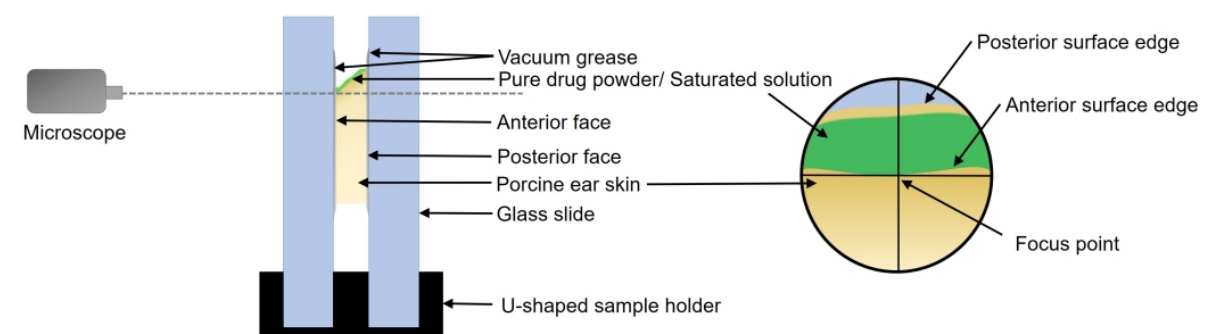

A microscope focuses at the anterior skin surface edge adjacent to it. Scans are carried out only if the anterior surface edge adjacent to the microscope is at a lower position than the posterior surface edge.

\section{8}
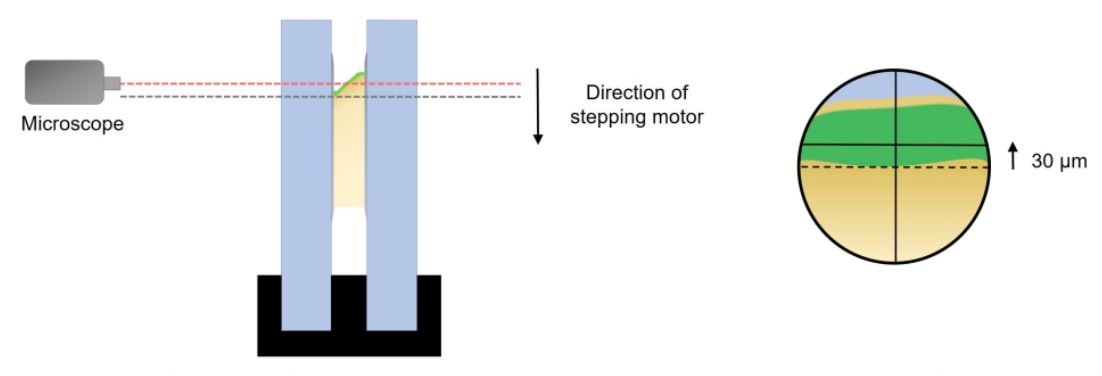

The sample holder moves down using a stepping motor to allow a scan starting at a distance of $30 \mu \mathrm{m}$ above the anterior surface edge.

$$
\text { C }
$$
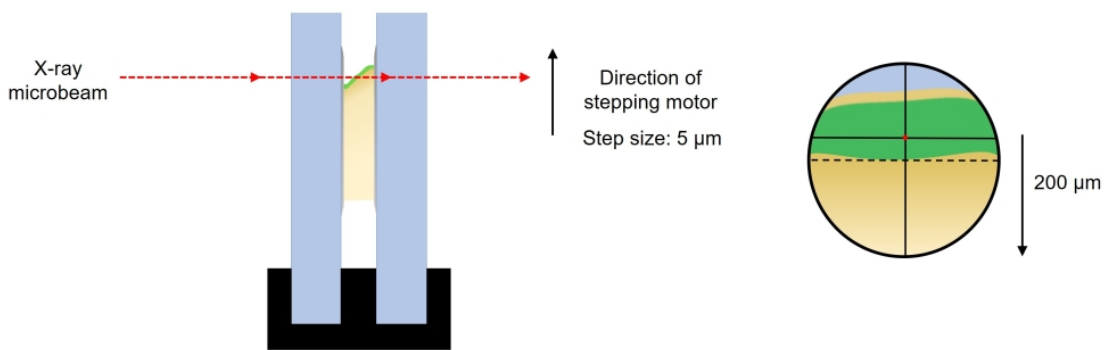

The microscope moves away from the scanning position before the X-ray microbeam impinges the sample with a step size of $5 \mu \mathrm{m}$, scanning vertically down to a total sequential series of $200 \mu \mathrm{m}$. All steps are repeated horizontally across the skin sample.

Figure 2 Schematic of the sample holder mounted with porcine ear skin. The circle on the right shows the view from the anterior cross-sectioned face of skin perpendicular to the microscope as well as the X-ray microbeam.

\section{$638 \times 732 \mathrm{~mm}(150 \times 150 \mathrm{DPI})$}



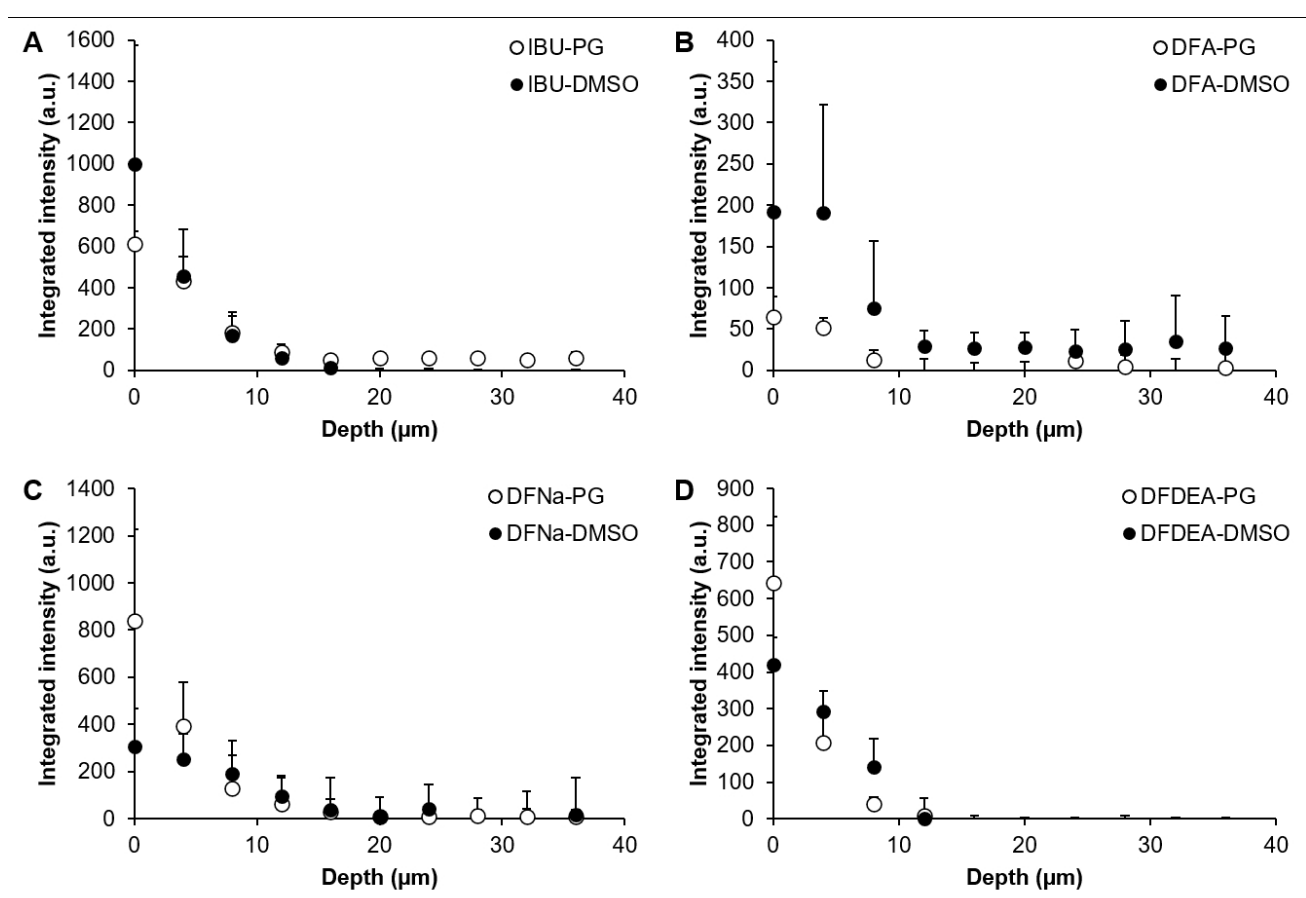

Figure 3 CRS depth profiles of (A) IBU, (B) DFA, (C) DF Na and (D) DF DEA after 30-min application of respective saturated solutions in PG $(\circ)$ and DMSO $(\bullet)$ to porcine ear skin $(n=8$, mean + SD) 

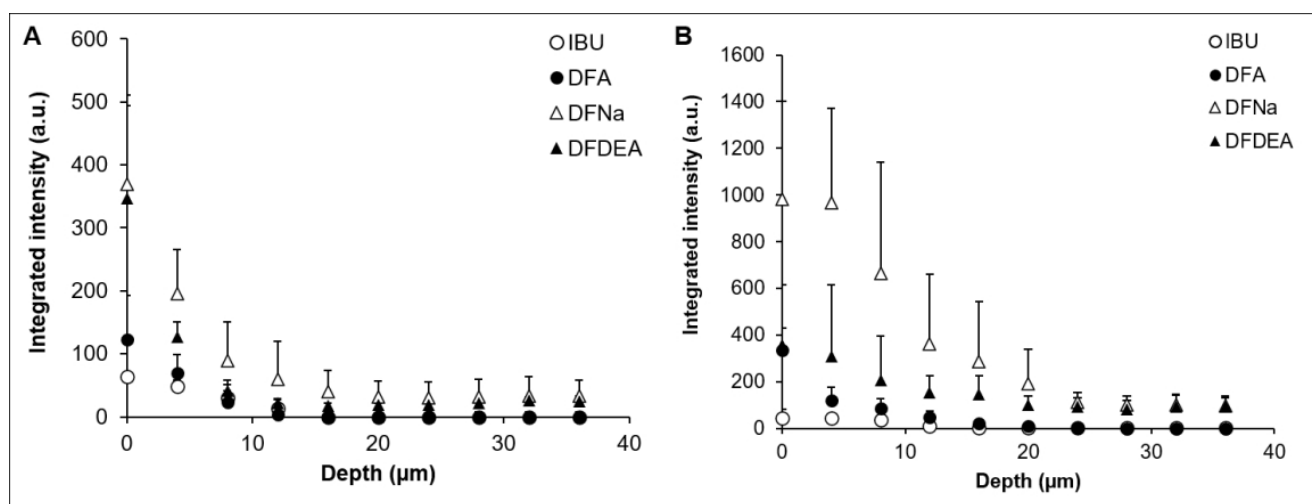

Figure 4 CRS depth profiles of (A) PG and (B) DMSO after 30-min application of various saturated drug solutions $(n=8$, mean $+S D)$ 


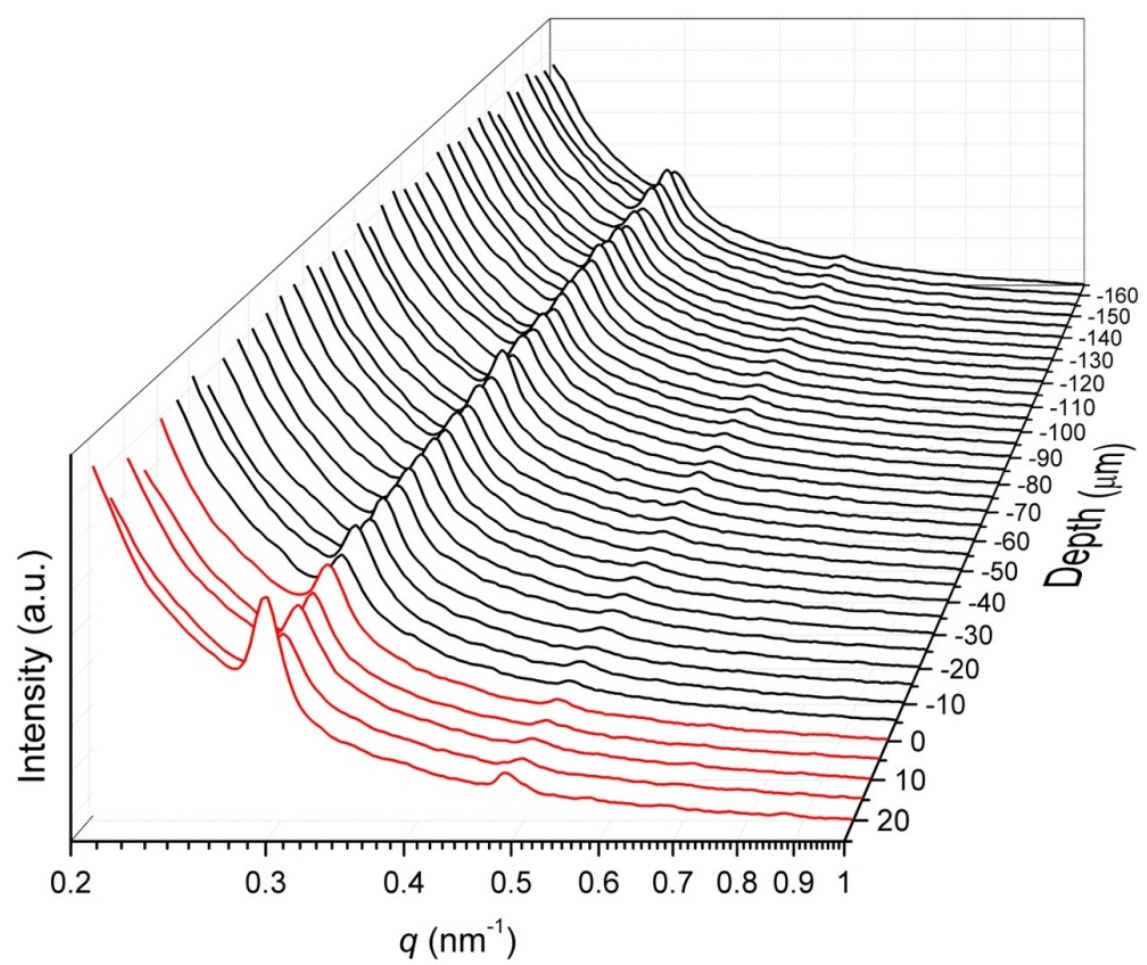

Figure 5 SAXS scattering profiles of cross-sectioned porcine ear skin as a function of depth (step size $=5$ $\mu \mathrm{m})$. The red and black curves indicate the scans at/above $(20$ to $0 \mu \mathrm{m})$ and below $(-5$ to $-165 \mu \mathrm{m})$ the anterior skin surface edge, respectively. The intensities are in arbitrary units.

$248 \times 190 \mathrm{~mm}(150 \times 150 \mathrm{DPI})$ 

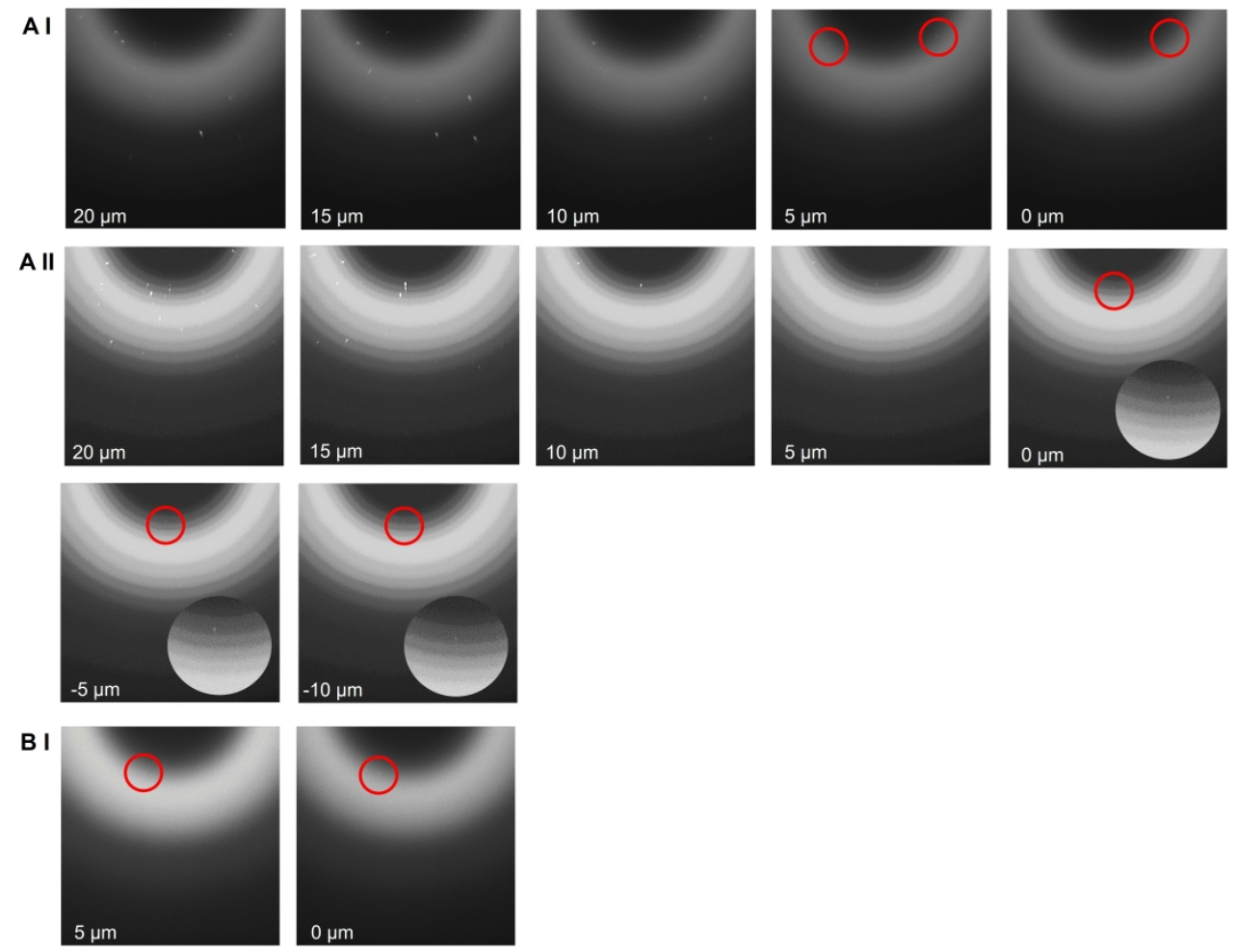

B II
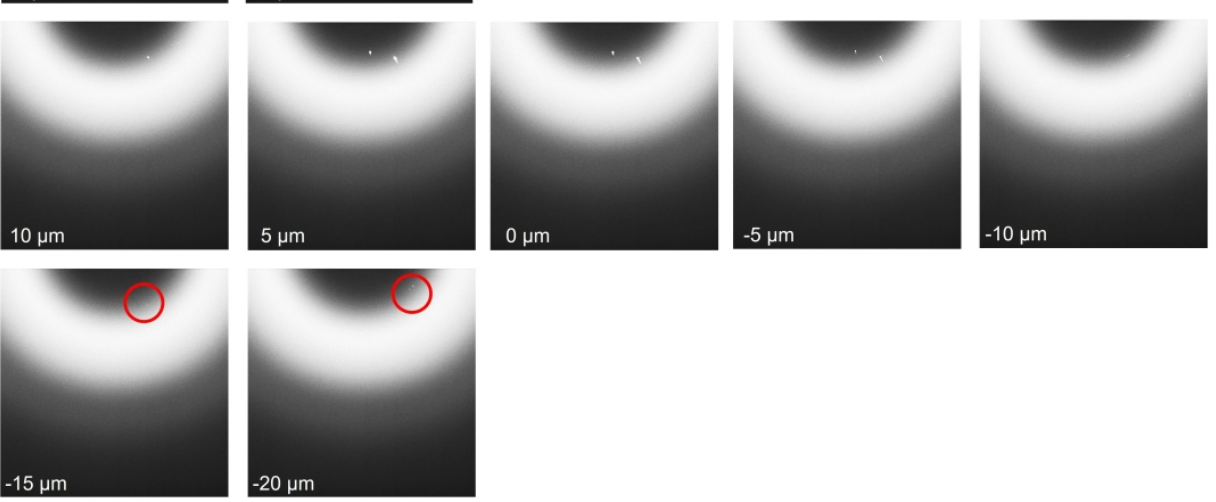

Figure 6 WAXS diffraction patterns of drug crystals after application of saturated solutions of IBU in (A) PG and $(B)$ DMSO $(n=2)$. Weak reflections are enlarged in the same figure or highlighted in the red circle.

$837 \times 985 \mathrm{~mm}(150 \times 150 \mathrm{DPI})$ 
I
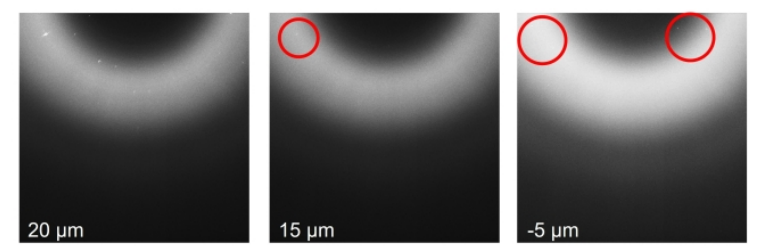

II
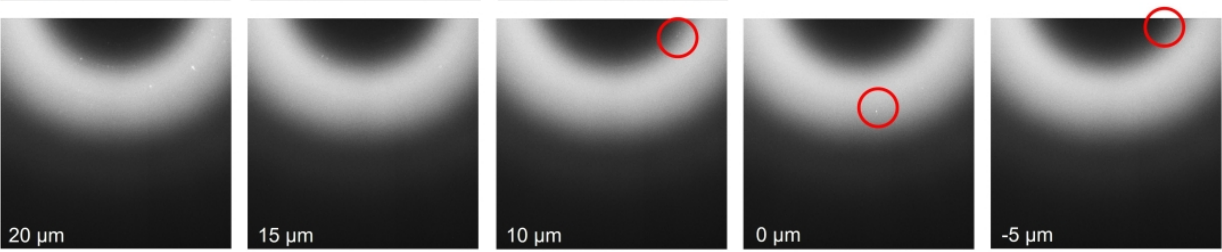

Figure 7 WAXS diffraction patterns of drug crystals after application of a saturated solution of DFA in DMSO $(n=2)$. Weak reflections are highlighted in the red circle.

$826 \times 331 \mathrm{~mm}(150 \times 150 \mathrm{DPI})$ 

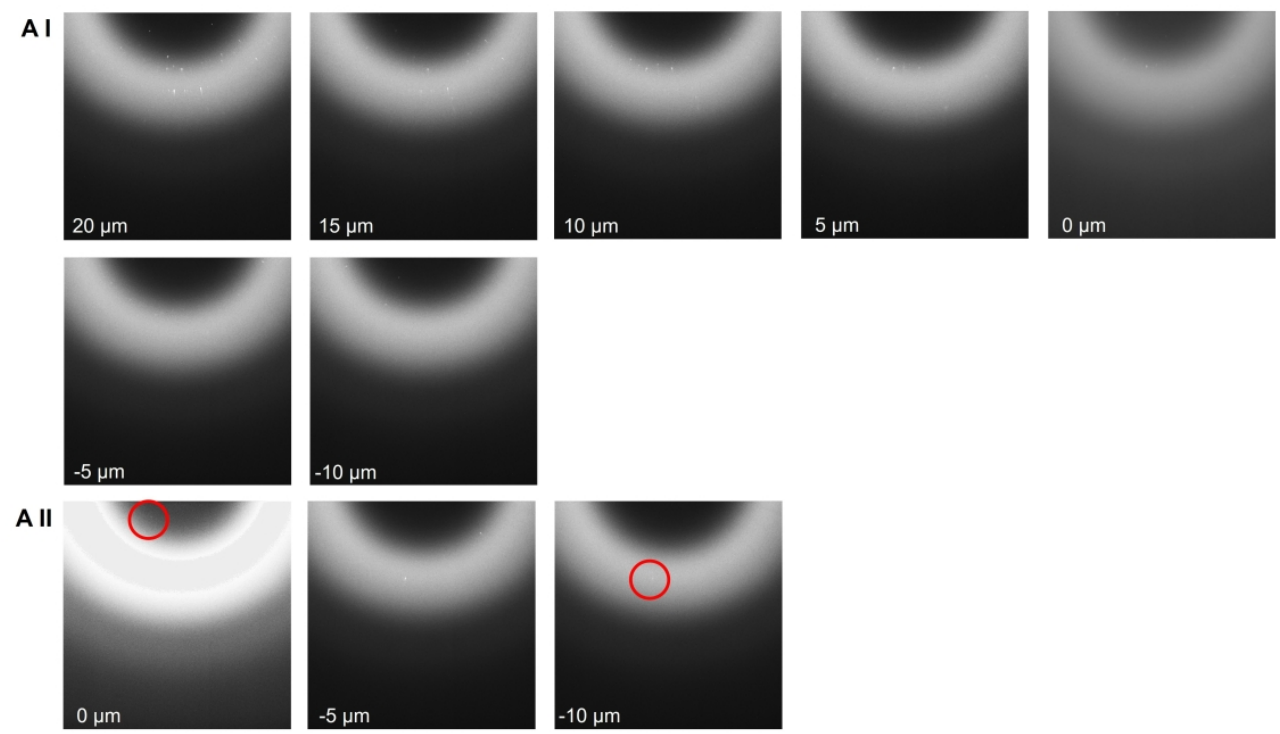

B I
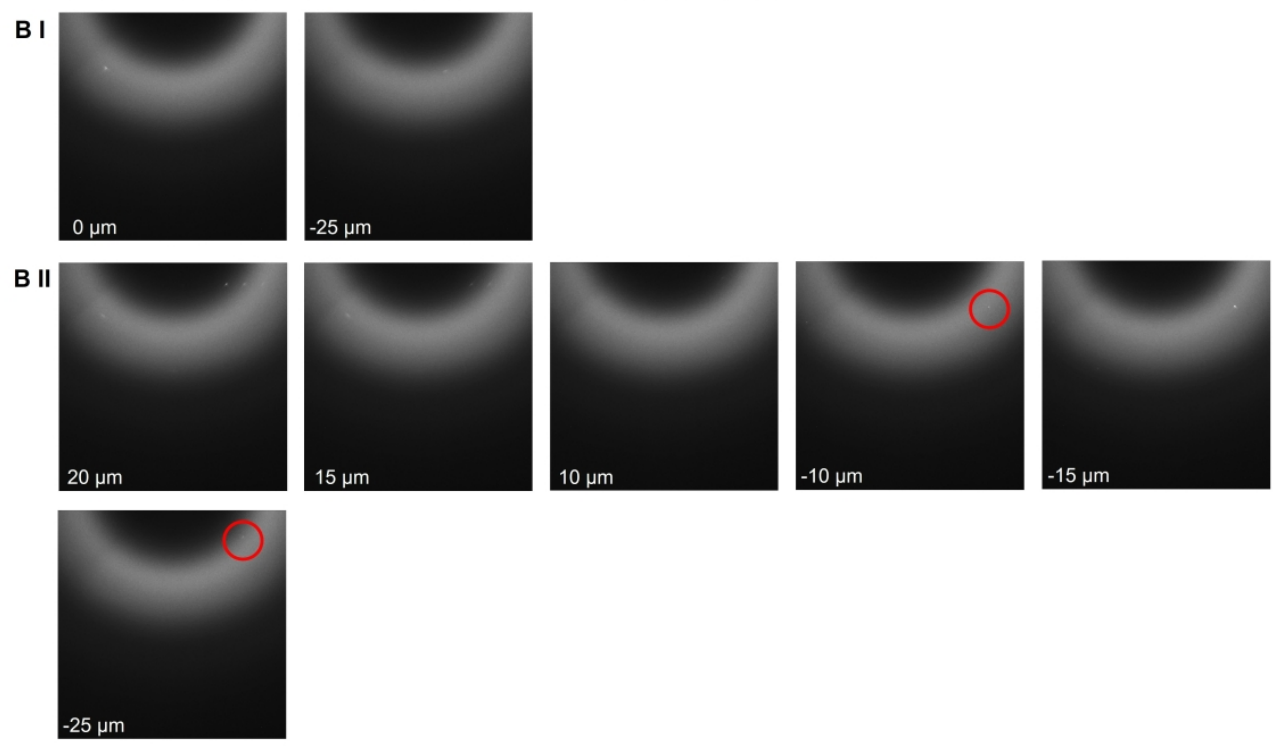

Figure 8 WAXS diffraction patterns of drug crystals after application of saturated solutions of DF Na in (A) PG and (B) DMSO $(n=2)$. Weak reflections are highlighted in the red circle.

$836 \times 984 \mathrm{~mm}(150 \times 150 \mathrm{DPI})$ 
A I
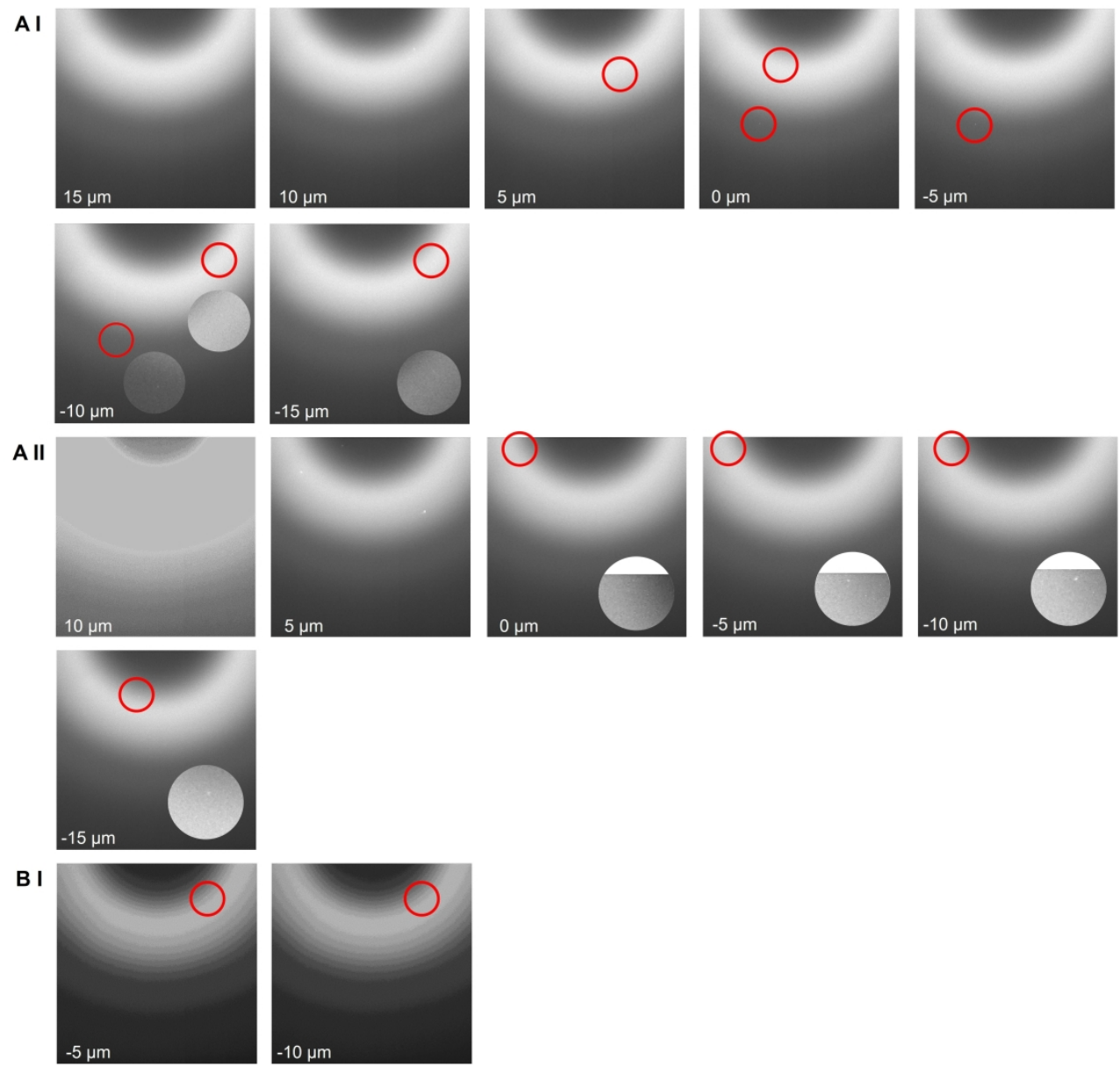

B II
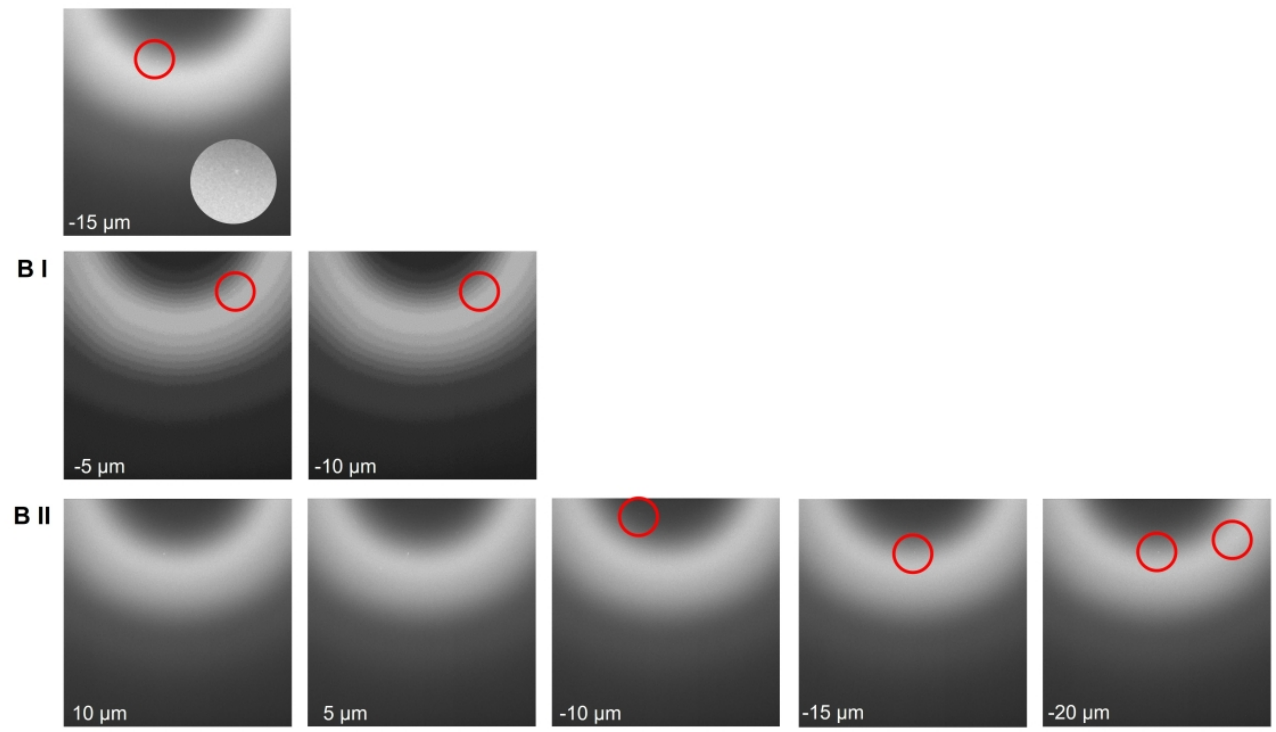

Figure 9 WAXS diffraction patterns of drug crystals after application of a saturated solution of DF DEA in (A) PG and (B) DMSO $(n=2)$. Weak reflections are enlarged in the same figure or highlighted in the red circle.

$836 \times 968 \mathrm{~mm}(150 \times 150$ DPI $)$ 
Ibuprofen (IBU)

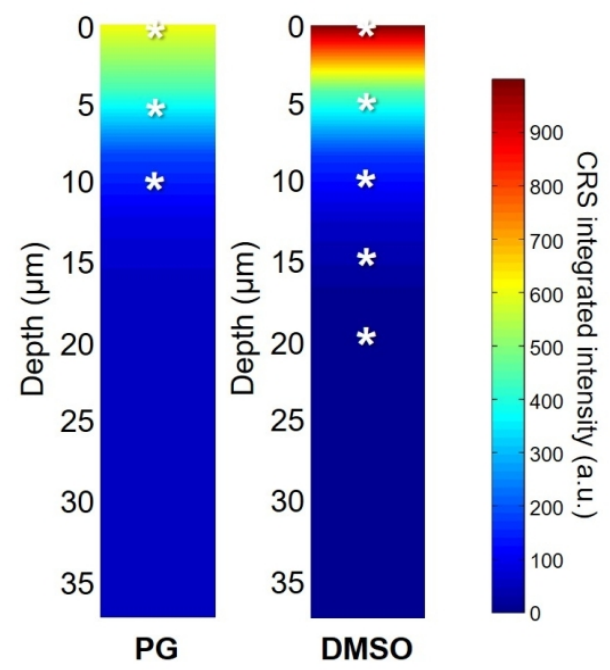

Diclofenac sodium (DFNa)

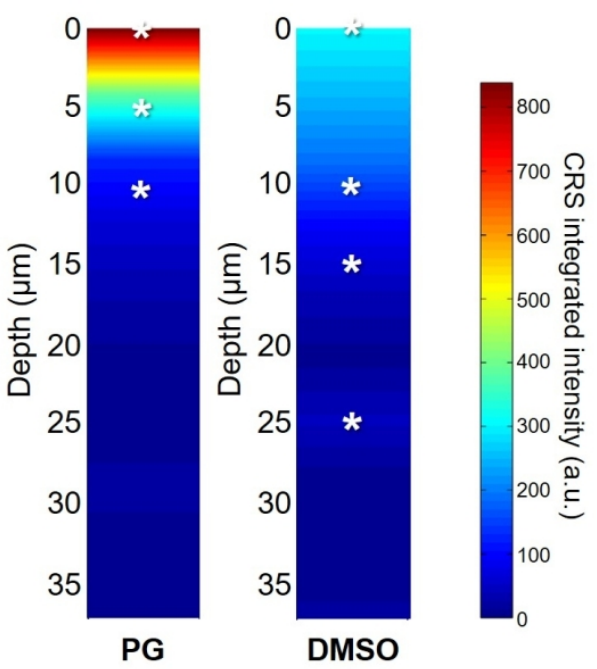

Diclofenac acid (DFA)

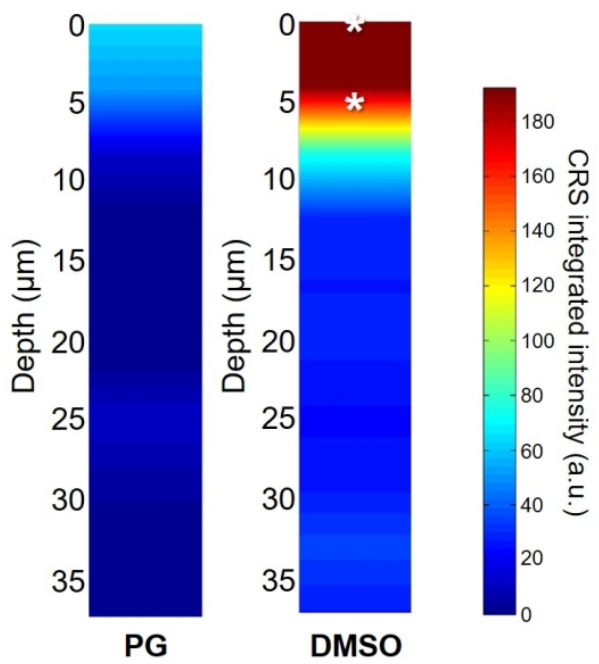

Diclofenac diethylamine (DFDEA)

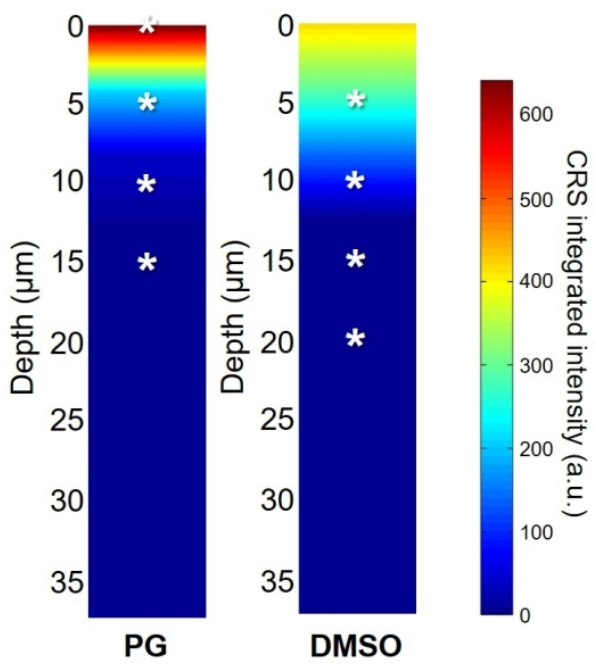

Figure 10 CRS depth profiles following the application of various saturated solutions in PG and DMSO to porcine ear skin and depth profiles for drug crystal diffraction $\left(^{*}\right)$ in the WAXS diffraction profiles

$$
263 \times 320 \mathrm{~mm}(150 \times 150 \text { DPI })
$$




\section{Supplemental material}

\section{Profiling of drug crystallization in the skin}

Choon Fu Goh a, b*, Ben J. Boyd c, Duncan Q.M. Craig ${ }^{\mathrm{b}}$, Majella E. Lane ${ }^{\mathrm{b}}$

a Discipline of Pharmaceutical Technology, School of Pharmaceutical Sciences, Universiti Sains Malaysia, 11800 Minden, Penang, Malaysia

b Department of Pharmaceutics, UCL School of Pharmacy, 29-39 Brunswick Square, London WC1N 1AX United Kingdom

c Drug Delivery, Disposition and Dynamics, Monash Institute of Pharmaceutical Sciences, Monash University, Parkville, Victoria, Australia

${ }^{*}$ Corresponding author: present address: Discipline of Pharmaceutical Technology, School of Pharmaceutical Sciences, Universiti Sains Malaysia, 11800 Minden, Penang, Malaysia.; Email: choonfugoh@usm.my 


\section{WAXS diffraction patterns: Pure drug crystals (Figure S1)}
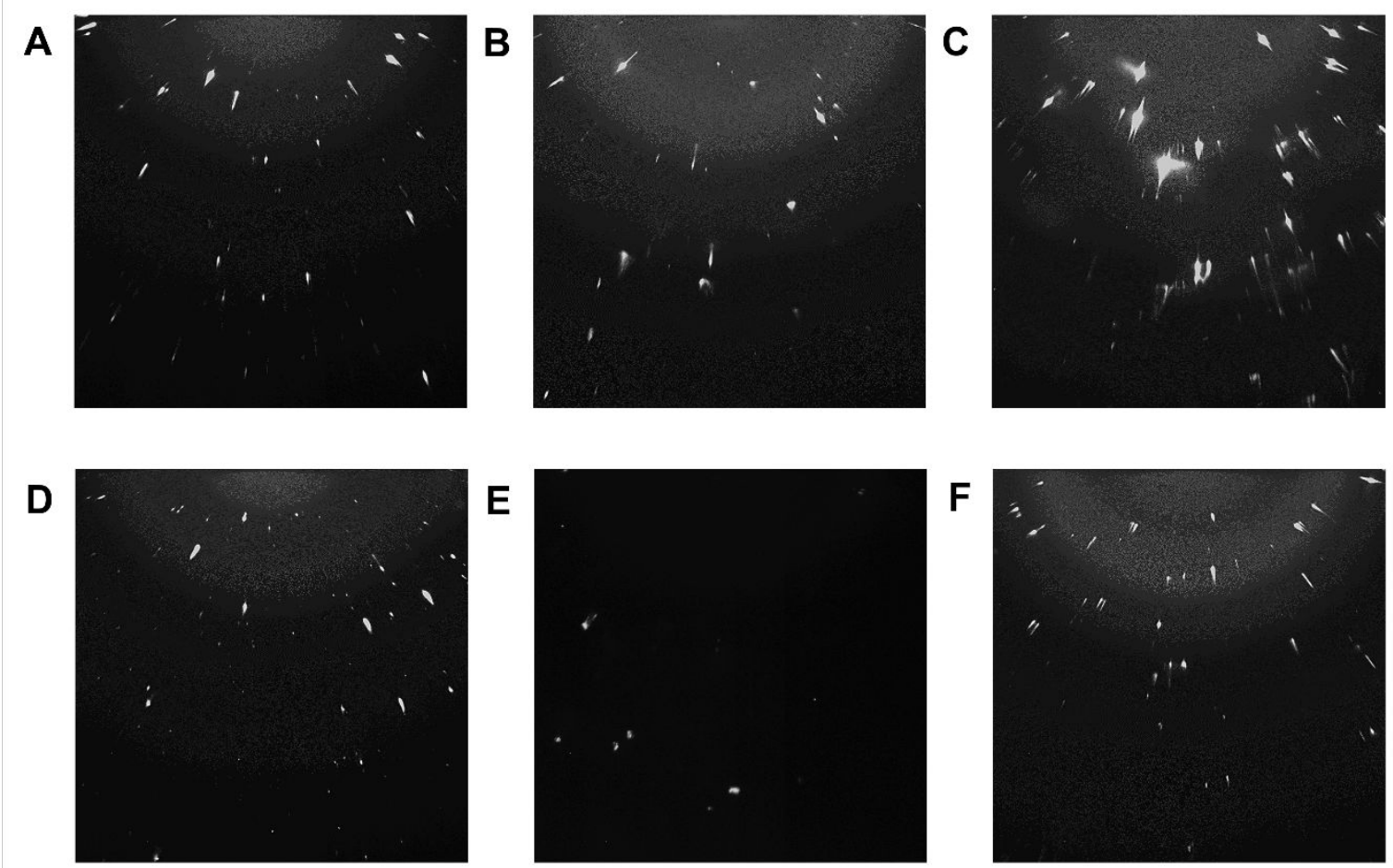

G
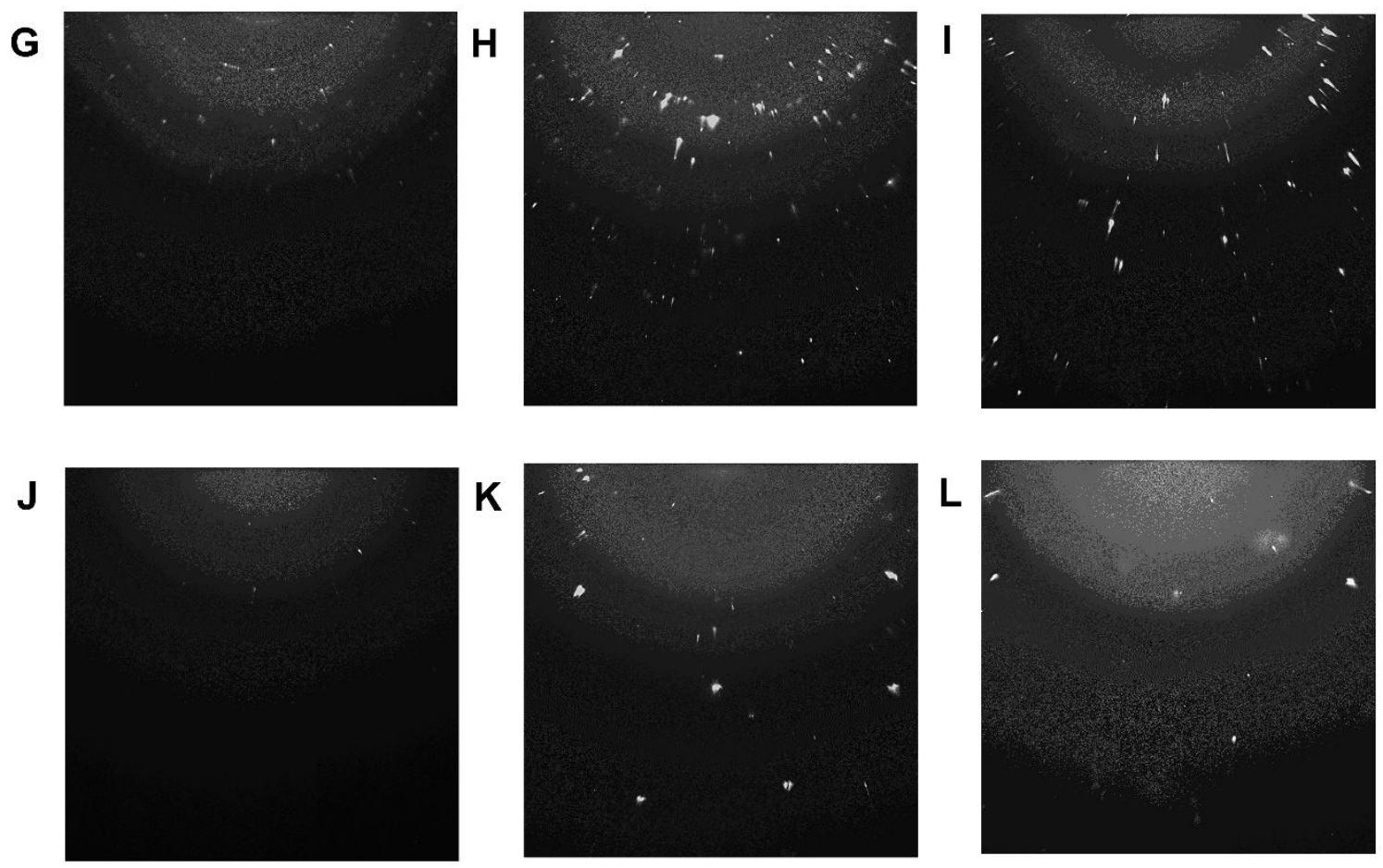

Figure S1 WAXS diffraction patterns of (A) IBU pure drug powder, (B) IBU-PG crystals, (C) IBU-DMSO crystals, (D) DFA pure drug powder, (E) DFA-PG crystals, (F) DFA-DMSO crystals, (G) DF Na pure drug powder, (H) DF Na-PG crystals, (I) DF Na-DMSO crystals, (J) DF DEA pure drug powder, (K) DF DEA-PG crystals and (L) DF DEA-DMSO crystals 


\section{SAXS and WAXS* scattering profiles: Validation of SAXS/WAXS experimental set up (Figure S2 and S3)}

*WAXS profiles without drug crystal diffraction not included

A

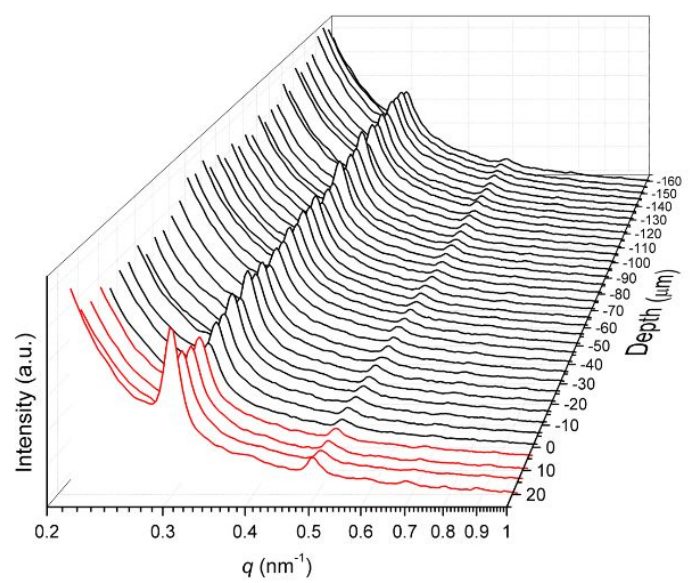

B

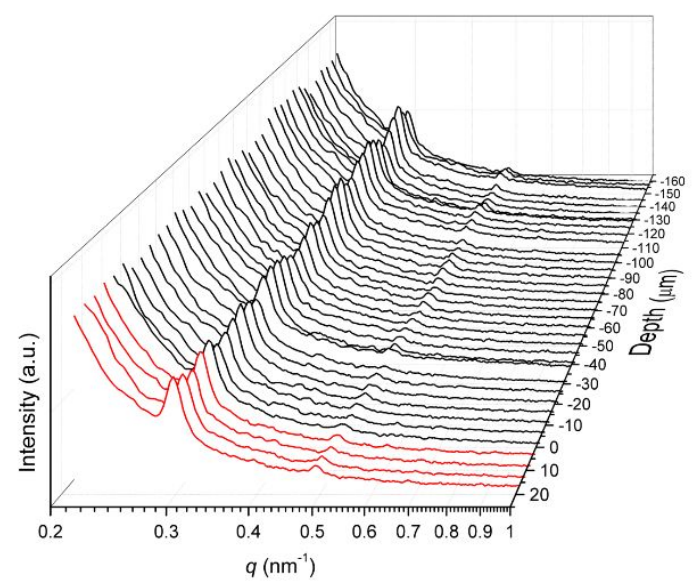

Figure S2 SAXS scattering profiles of the cross-sectioned porcine skin as a function of depth (step size $=5 \mu \mathrm{m}$ ) for validation purposes using (A) IBU and (B) DFA. The red and black curves indicate the scans at/above (20 to $0 \mu \mathrm{m})$ and below $(-5$ to $-165 \mu \mathrm{m})$ the anterior skin surface edge, respectively. The intensities are in arbitrary units.

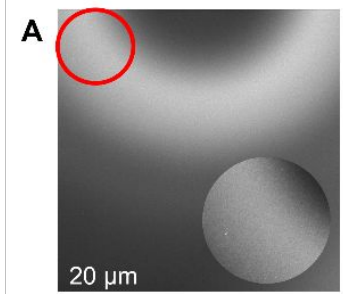

B

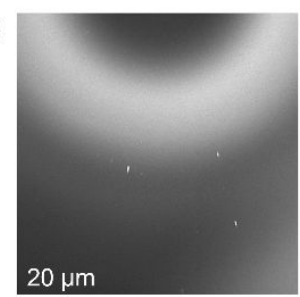

C

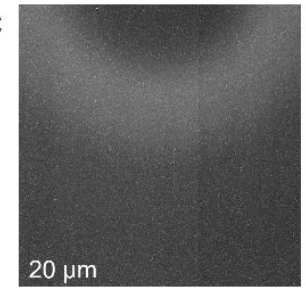

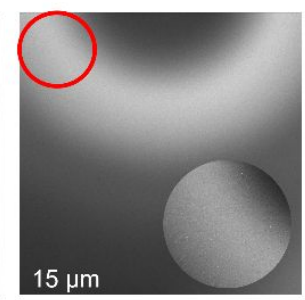
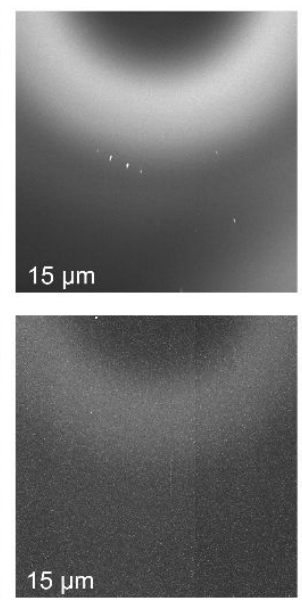
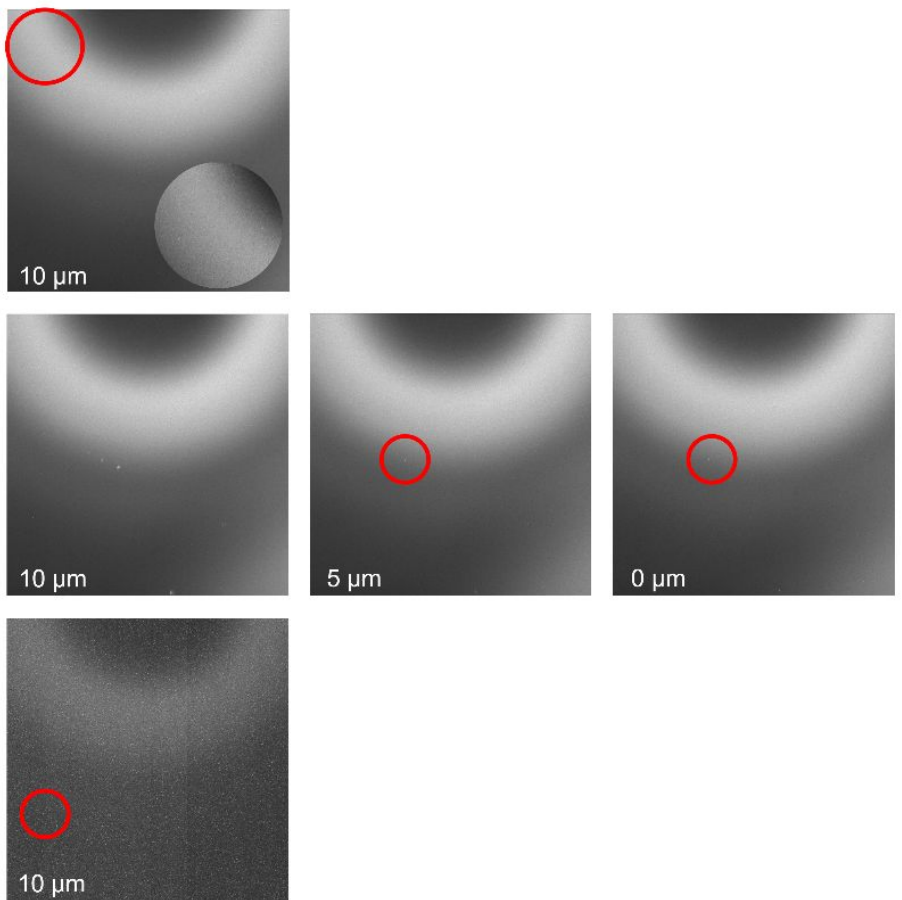

Figure S3 WAXS diffraction patterns of pure drug powder, (A - B) IBU and (C) DFA, sprinkled onto porcine skin for validation purposes. Weak reflections are enlarged in the same figure and/or highlighted in the red circle. 

porcine skin

A I

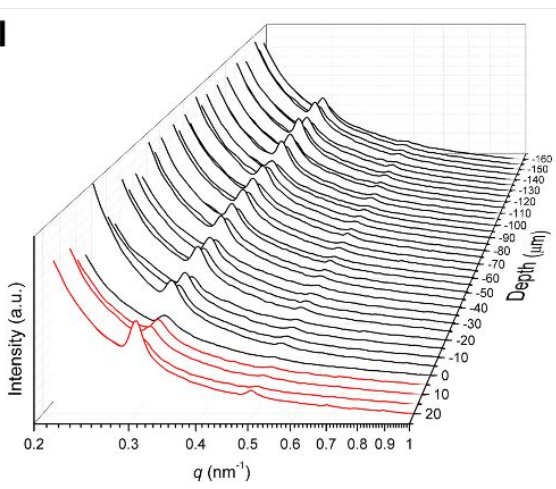

B I

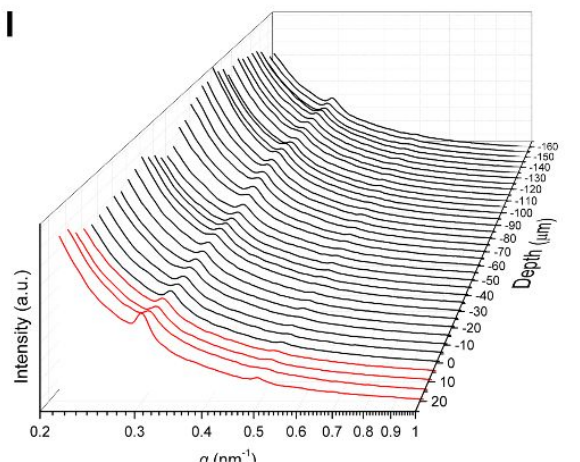

C I

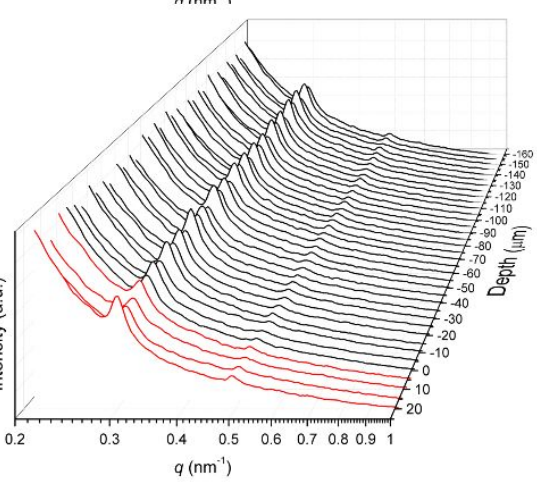

D I

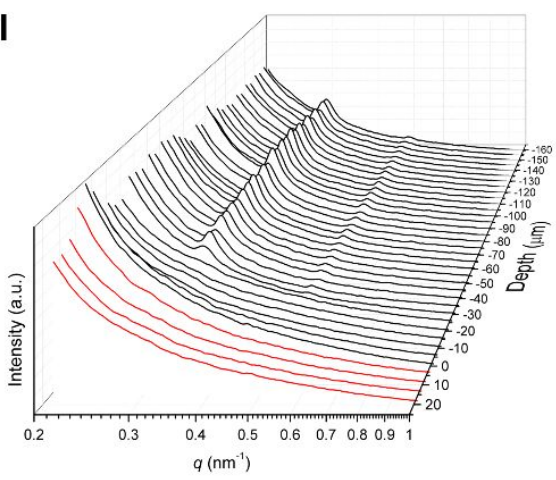

A II

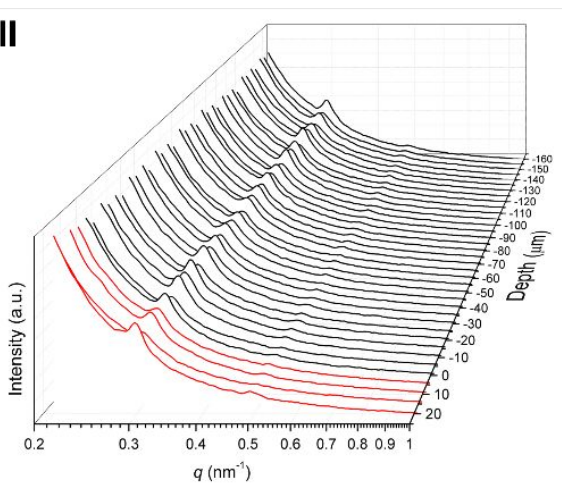

B II

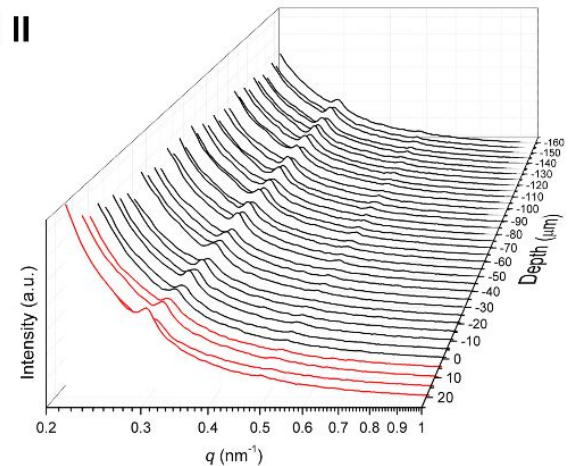

C II

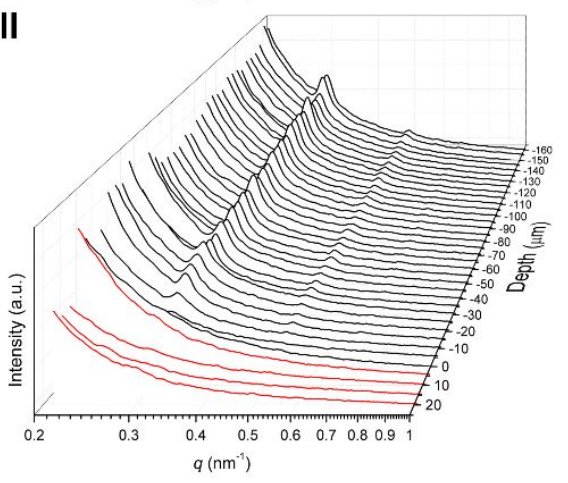

D II

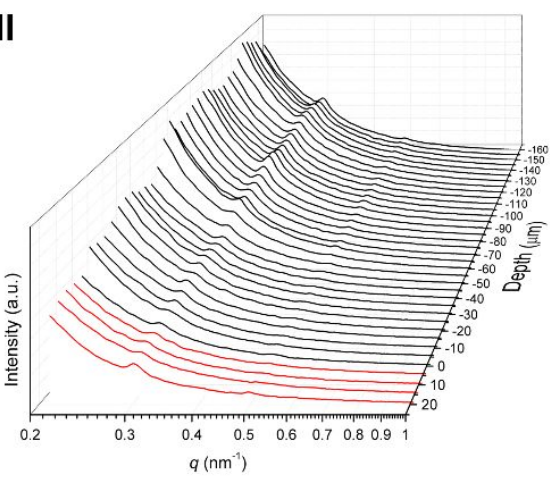

Figure S4 SAXS scattering profiles of cross-sectioned porcine skin as a function of depth (step size $=5 \mu \mathrm{m}$ ) after application of saturated solutions of (A) IBU, (B) DFA, (C) DF Na and (D) DF DEA in (I) PG and (II) DMSO. The red and black curves indicate the scans at/above $(20$ to $0 \mu \mathrm{m})$ and below $(-5$ to $-165 \mu \mathrm{m})$ the anterior skin surface edge, respectively. The intensities are in arbitrary units. 


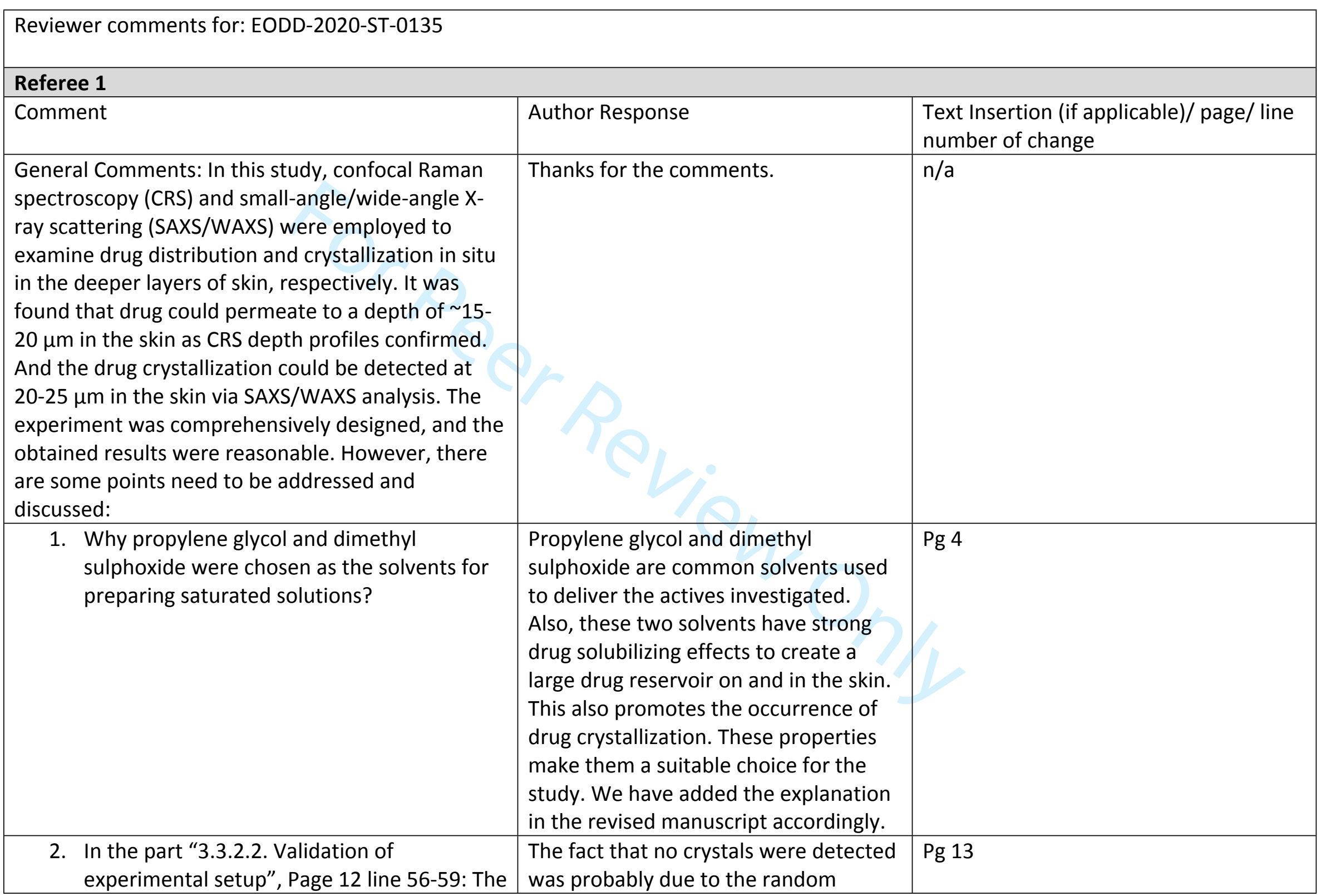




\begin{tabular}{|c|c|c|c|}
\hline & $\begin{array}{l}\text { pure drug powder was applied onto the } \\
\text { surface of the skin samples previously, } \\
\text { however, in two runs of WAXS scattering, } \\
\text { diffraction from drug crystals of diclofenac } \\
\text { acid was only detected in one of the } \\
\text { samples, why there were no crystals } \\
\text { detected in another run? Please explain the } \\
\text { reason. }\end{array}$ & $\begin{array}{l}\text { application of drug powder samples of } \\
\text { different particle sizes. We have added } \\
\text { the explanation in the revised } \\
\text { manuscript accordingly. }\end{array}$ & \\
\hline 4. & $\begin{array}{l}\text { Figures } 3 \text { and Figure } 4 \text { applied in this } \\
\text { manuscript should be reproduced, the } \\
\text { coordinate is partially obscured. }\end{array}$ & $\begin{array}{l}\text { The figures were distorted during PDF } \\
\text { conversion. The figures have been } \\
\text { uploaded separately. }\end{array}$ & Pg 24 onwards \\
\hline 5. & $\begin{array}{l}\text { In the explanation of Figure } 7 \text { and Figure 8, } \\
\text { "Weak reflections are enlarged in the same } \\
\text { figure or highlighted in the red circle." } \\
\text { However, there were no enlarged figures in } \\
\text { these two figures. In addition, the red circles } \\
\text { in the figures (Figure 6-9) are not obvious } \\
\text { enough. }\end{array}$ & We have amended accordingly. & Pg 24 onwards \\
\hline 6. & $\begin{array}{l}\text { In Figure 10, what is the meaning of the } \\
\text { ruler? Please make it clear in the caption. } \\
\text { And the font size of numbers is too small to } \\
\text { see clearly. }\end{array}$ & $\begin{array}{l}\text { The ruler indicates the intensity of the } \\
\text { Raman signal. We have amended } \\
\text { accordingly. }\end{array}$ & Pg 24 onwards \\
\hline 7. & $\begin{array}{l}\text { Figure S2 and Figure S4 in this manuscript } \\
\text { are not clear enough, these figures need to } \\
\text { be provided at a sufficiently high resolution } \\
\text { to ensure the high quality of this manuscript. }\end{array}$ & $\begin{array}{l}\text { We have amended and submitted the } \\
\text { figures separately. }\end{array}$ & Pg 24 onwards \\
\hline
\end{tabular}




\begin{tabular}{|c|c|c|}
\hline \multicolumn{3}{|l|}{ Referee 2} \\
\hline Comment & Author response & $\begin{array}{l}\text { Text Insertion (if applicable)/ page/ line } \\
\text { number of change }\end{array}$ \\
\hline $\begin{array}{l}\text { General Comments: The study proposal to } \\
\text { understand if drug crystallization occurs during the } \\
\text { transport through the skin is interesting, but the } \\
\text { authors should have also evaluated the } \\
\text { crystallization behavior of the drugs in solution (e.g. } \\
\text { temperature changes) and if solvent changes } \\
\text { (DMSO and PG for aqueous fluids) could induce } \\
\text { drug crystallization. This fact explains because the } \\
\text { discussion of the results is limited, and the study } \\
\text { conclusion is not attractive. }\end{array}$ & $\begin{array}{l}\text { Thanks for the comments. We have } \\
\text { amended Discussion and Conclusions } \\
\text { accordingly. }\end{array}$ & $\mathrm{n} / \mathrm{a}$ \\
\hline $\begin{array}{l}\text { 1. INTRODUCTION } \\
\text { A) The sentence "More recently the } \\
\text { possibility of actives being stranded in the } \\
\text { SC because of crystallization in the lipid } \\
\text { bilayers has also been confirmed" needs to } \\
\text { be supported by more references. } \\
\text { B) If the understanding of drug } \\
\text { crystallization in and on the skin had already } \\
\text { been reported, what is the innovation from } \\
\text { this manuscript? Please clarify! } \\
\text { C) The reasons to select these drugs for the } \\
\text { study need to be presented. }\end{array}$ & $\begin{array}{l}\text { A) The relevant references were added } \\
\text { accordingly. } \\
\text { B) The detection of drug crystallization } \\
\text { in and on the skin still remains } \\
\text { challenging due to the complexity of } \\
\text { the organic tissues and sensitivity of } \\
\text { instruments used which have been } \\
\text { explained. Therefore, even though the } \\
\text { problem has been addressed, those } \\
\text { reports involved invasive approaches } \\
\text { and the detection was found in the } \\
\text { superficial skin layers. We have added } \\
\text { the explanation accordingly. } \\
\text { C) We have added the explanation } \\
\text { accordingly. }\end{array}$ & Pg 3-4 \\
\hline
\end{tabular}




\begin{tabular}{|c|c|c|}
\hline $\begin{array}{l}\text { A) Saturated solutions were prepared at } \\
32 \text { oC. After this procedure, I think the } \\
\text { authors have stored these solutions at room } \\
\text { temperature. Could any drug crystallization } \\
\text { be induced due to this temperature } \\
\text { difference? } \\
\text { B) Why were DMSO and PG selected as } \\
\text { solubilizing media? Wouldn't it be more } \\
\text { rational to consider some buffering } \\
\text { solution? High concentrations of DMSO are } \\
\text { well-known to affect the viability and } \\
\text { structure of biological tissues. } \\
\text { C) Why did the authors define } 30 \text { min as the } \\
\text { exposure time to the different samples? } \\
\text { What is the lag time required for these drugs } \\
\text { to cross the tissue? } \\
\text { D) More details on the tissue preparation } \\
\text { need to be included in the method section. } \\
\text { E) Was the fresh or frozen skin used in the } \\
\text { assays? } \\
\text { F) Why did the authors not consider a } \\
\text { method traditionally used in drug } \\
\text { permeation assays (example: diffusion cells } \\
\text { of the Franz type)? }\end{array}$ & $\begin{array}{l}\text { A) The saturated solutions were kept at } \\
32^{\circ} \mathrm{C} \text { until the solutions were loaded on } \\
\text { the skin sample. We acknowledged the } \\
\text { fact that temperature difference will } \\
\text { induce drug crystallization. } \\
\text { B) These solvents have been used to } \\
\text { investigate drug crystallization } \\
\text { phenomena in the skin. They have } \\
\text { excellent drug solubilizing effects } \\
\text { which maximizes the chances of drug } \\
\text { crystallisation to be detected. We have } \\
\text { added the explanation accordingly. } \\
\text { C) Our lab results (not shown) have } \\
\text { demonstrated the potential of the } \\
\text { relevant saturated drug solutions to } \\
\text { induce drug crystallisation within } 30 \\
\text { min. This explanation was added in the } \\
\text { Introduction together with the } \\
\text { previous comment. } \\
\text { D) This was mentioned in Section } 2.1 \\
\text { and references were provided to } \\
\text { confirm the similar procedure that was } \\
\text { used. } \\
\text { E) Frozen skin was used. This was } \\
\text { mentioned in Section } 2.1 .\end{array}$ & Pg 5-8 \\
\hline
\end{tabular}




\begin{tabular}{|c|c|c|}
\hline & $\begin{array}{l}\text { F) We attempted the use of Franz } \\
\text { diffusion cell studies for the work. } \\
\text { However, during the excision of the } \\
\text { skin samples after permeation studies, } \\
\text { drug crystals were persistently found in } \\
\text { the deeper skin layers (even deeper } \\
\text { than the current results). This was then } \\
\text { confirmed as resulting from the } \\
\text { contamination of drug crystals from } \\
\text { the skin surface during processing. The } \\
\text { current approach reported has no } \\
\text { contamination issues and was } \\
\text { validated as detailed in the manuscript. }\end{array}$ & \\
\hline $\begin{array}{l}\text { 3. RESULTS } \\
\text { A) The authors have stated that drugs } \\
\text { penetrated the skin up to } 15-20 \mu \mathrm{m} \text {. No } \\
\text { enough evidences in the manuscript may be } \\
\text { found for this statement. What is the } \\
\text { detection limit of the CRS technique used to } \\
\text { monitor the drug distribution? } \\
\text { B) In the sentence "both the IBU-PG and } \\
\text { IBU-DMSO saturated solutions showed a } \\
\text { similar drug distribution profile but a very } \\
\text { strong drug signal was found close to the } \\
\text { skin surface (depth zero) for the DMSO } \\
\text { solution", was the drug amount normalized? } \\
\text { C) For both IBU saturated solutions, only one } \\
\text { of the two replicates showed the diffraction } \\
\text { of crystals in the skin. Weren't these } \\
\text { analyzes performed in triplicate? }\end{array}$ & $\begin{array}{l}\text { A) The CRS data were measured as a } \\
\text { function of depth. The results are } \\
\text { indicated in Fig } 3 \text { where the } x \text { axis } \\
\text { reflects the depth of the scan. The } \\
\text { step-scan was also indicated in the } \\
\text { Method. The spectral resolution is } 4 \\
\mathrm{~cm}^{-1} \text {. The detection and integration of } \\
\text { selected peak with normalization to } \\
\text { skin keratin were achieved with the } \\
\text { built-in software. The limit of detection } \\
\text { relies on the software in differentiating } \\
\text { the drug peak from keratin peak. As } \\
\text { the calibration of absolute drug } \\
\text { content in the skin remains } \\
\text { challenging, the current setup did not } \\
\text { report the actual drug amount and the }\end{array}$ & Pg 9-14 \\
\hline
\end{tabular}




\begin{tabular}{|c|c|}
\hline $\begin{array}{l}\text { D) Why were microscopic techniques (e.g. } \\
\text { SEM) not used to support the SAXS and } \\
\text { WAXS results? } \\
\text { E) Were SAXS and WAXS analyzes performed } \\
\text { immediately after the contact of saturated } \\
\text { solutions with the skin or was there any } \\
\text { waiting time? If some specific waiting time } \\
\text { was considered, under what conditions were } \\
\text { the skin stored? Please clarify! }\end{array}$ & $\begin{array}{l}\text { exact limit of detection cannot be fully } \\
\text { explored. However, it remains } \\
\text { important to show the drug } \\
\text { distribution in the skin in a.u.. } \\
\text { B) Yes, this was indicated in the } \\
\text { Method: 'The in vitro drug (and } \\
\text { solvent) signal from the Raman skin } \\
\text { spectrum was normalized to the } \\
\text { keratin content because the absolute } \\
\text { Raman signal intensity of in vitro skin } \\
\text { spectra decreases in the deeper layers } \\
\text { of the skin.'. } \\
\text { C) Given that drug crystallization is a } \\
\text { random process, we attempted more } \\
\text { than } 10 \text { scans to record the } \\
\text { diffractions. This part was indicated in } \\
\text { the Method: 'These steps were carried } \\
\text { out repetitively (at least } 10 \text { times) and } \\
\text { horizontally across the skin sample.'. } \\
\text { The results shown are only the selected } \\
\text { diffraction data. } \\
\text { D) SEM was explored previously in our } \\
\text { work together with probe-based } \\
\text { nanocharacterization. This technique is } \\
\text { thus not employed in this work. } \\
\text { E) There is no waiting time. The sample } \\
\text { was scanned immediately using }\end{array}$ \\
\hline
\end{tabular}




\begin{tabular}{|c|c|c|}
\hline & $\begin{array}{l}\text { SAXS/WAXS. The total scan time for } \\
\text { each sample was maintained at } 30 \text { min } \\
\text { and the experiment was repeated from } \\
\text { the permeation step if any. We have } \\
\text { added the explanation accordingly. }\end{array}$ & \\
\hline $\begin{array}{l}\text { 4. DISCUSSION } \\
\text { A) What is the impact of the change of } \\
\text { medium (DMSO to biological fluid) on the } \\
\text { crystallization behavior of the drug? This } \\
\text { aspect needs to be discussed in detail. } \\
\text { B) Does the crystallization of the tested } \\
\text { drugs occur preferably in the dermis, viable } \\
\text { epidermis or stratum corneum? Please } \\
\text { consider that these tissue layers have } \\
\text { different levels of hydration. } \\
\text { C) Considering that the biological tissue } \\
\text { (skin) was not continuously hydrated, could } \\
\text { this not have an impact on the crystallization } \\
\text { of the drug? (reduction in water content } \\
\text { contributes to drug crystallization). Couldn't } \\
\text { this result be different from the one } \\
\text { observed physiologically? } \\
\text { D) Conditions/factors that induce the } \\
\text { crystallization of the drugs used in this } \\
\text { research should also be presented. }\end{array}$ & $\begin{array}{l}\text { A) We have added at the end of the } \\
\text { Discussion a section on the potential of } \\
\text { drug crystallization with current } \\
\text { commercial products. } \\
\text { B) Yes, we believe that drug } \\
\text { crystallization may happen in the viable } \\
\text { epidermis and beyond. We have added } \\
\text { the explanation accordingly. } \\
\text { C) We acknowledged that this work is } \\
\text { an in vitro study and cannot reflect the } \\
\text { actual events in vivo. The use of } \\
\text { SAXS/WAXS is not suitable for an in } \\
\text { vivo study as indicated in the } \\
\text { Discussion. However, this work is more } \\
\text { sensitive and provides an in situ } \\
\text { measurement compared with the } \\
\text { techniques explored previously. } \\
\text { D) We have added the discussion } \\
\text { accordingly. }\end{array}$ & Pg 15-17 \\
\hline
\end{tabular}




\begin{tabular}{|c|c|c|}
\hline Comment & \multirow{2}{*}{$\begin{array}{l}\text { Author response } \\
\text { Yes, this is correct. The travel funding } \\
\text { by ISAP has a grant number (ISP8044) } \\
\text { which has been added in the revised } \\
\text { manuscript accordingly. }\end{array}$} & \multirow{2}{*}{$\begin{array}{l}\text { Text Insertion (if applicable)/ page/ line } \\
\text { number of change } \\
\text { n/a }\end{array}$} \\
\hline $\begin{array}{l}\text { 1. Please could you confirm if the following } \\
\text { funding statement is correct, and insert any } \\
\text { relevant grant numbers, if applicable: } \\
\text { This work was supported by Ministry of } \\
\text { Education Malaysia for PhD funding of } \\
\text { Choon Fu Goh and travel funding provided } \\
\text { by the International Synchrotron Access } \\
\text { Program (ISAP) managed by the Australian } \\
\text { Synchrotron, part of ANSTO, and funded by } \\
\text { the Australian Government. }\end{array}$ & & \\
\hline $\begin{array}{l}\text { 2. Please could you confirm if the following } \\
\text { declaration of interests statement is correct: } \\
\text { CF Goh has disclosed PhD funding from the } \\
\text { Ministry of Education, Malaysia. B Boyd has } \\
\text { disclosed travel funding provided by the } \\
\text { International Synchrotron Access Program } \\
\text { (ISAP) managed by the Australian } \\
\text { Synchrotron, part of ANSTO, and funded by } \\
\text { the Australian Government. The authors } \\
\text { have no other relevant affiliations or } \\
\text { financial involvement with any organization } \\
\text { or entity with a financial interest in or } \\
\text { financial conflict with the subject matter or } \\
\text { materials discussed in the manuscript apart } \\
\text { from those disclosed. }\end{array}$ & Yes, this is correct. & $\mathrm{n} / \mathrm{a}$ \\
\hline $\begin{array}{l}\text { 3. Please ensure that, where necessary, } \\
\text { permission has been obtained for any re- } \\
\text { use/adaptation of figures and sent to us. If } \\
\text { any of the figures you have included are }\end{array}$ & No issue on this matter. & n/a \\
\hline
\end{tabular}




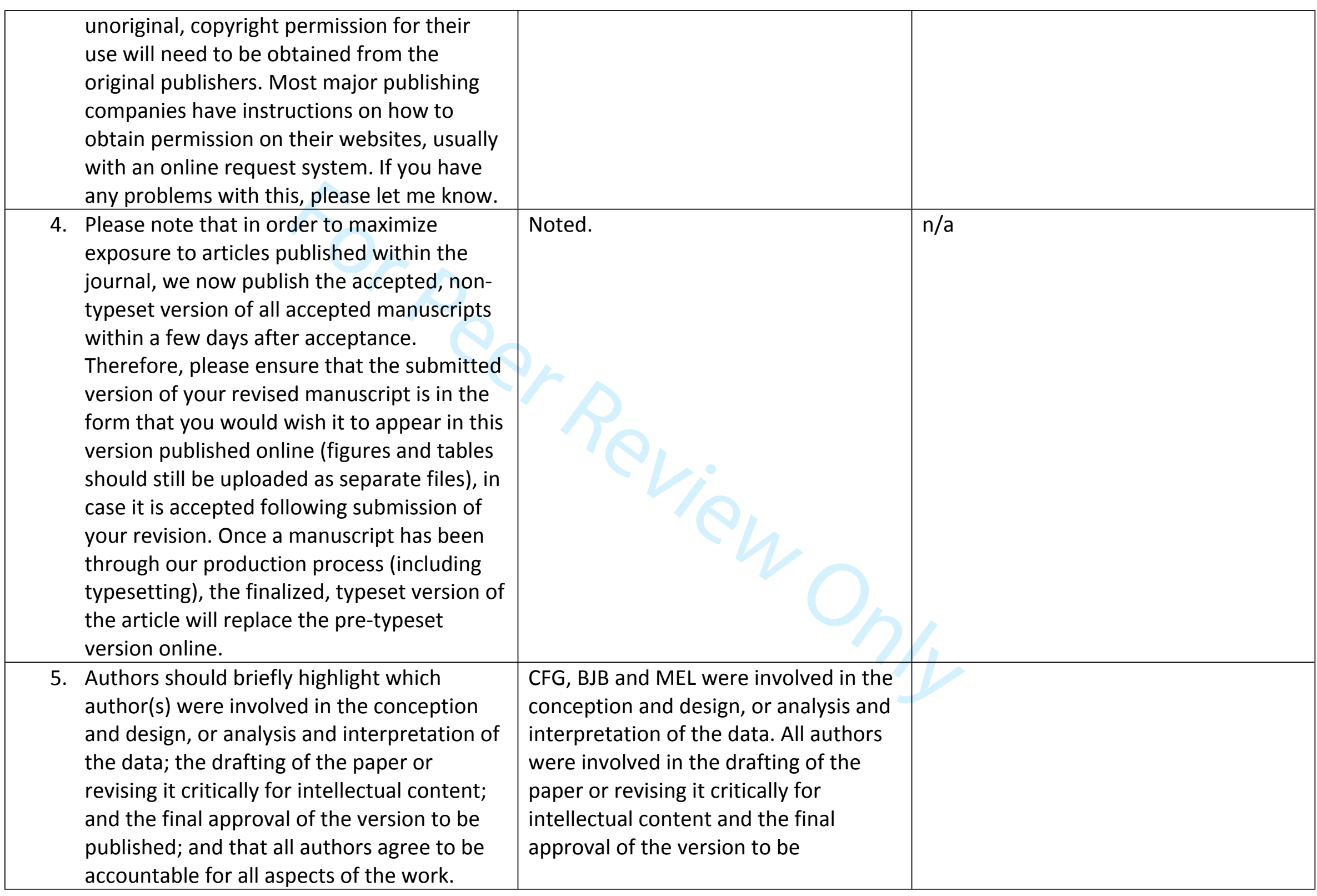




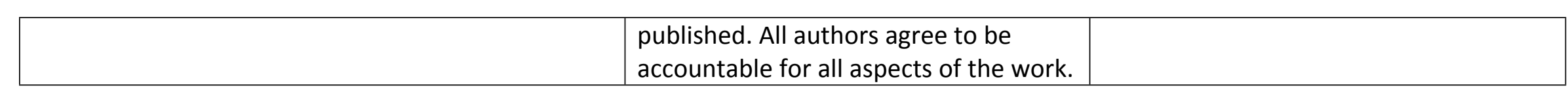

